\title{
Nanotechnology for treating osteoporotic vertebral fractures
}

\author{
This article was published in the following Dove Press journal: \\ International Journal of Nanomedicine \\ 13 August 2015 \\ Number of times this article has been viewed
}

\section{Chunxia Gaol,* \\ Donglei Wei ${ }^{1, *}$ \\ Huilin Yang' \\ Tao Chen ${ }^{2}$ \\ Lei Yang ${ }^{1,3}$}

'Department of Orthopaedic Surgery and Orthopaedic

Institute, First Affiliated Hospital,

${ }^{2}$ Robotics and Microsystems Center,

Collaborative Innovation Center of

Suzhou Nano Science and Technology,

Soochow University, Suzhou,

${ }^{3}$ Laboratory of Nonlinear Mechanics,

Institute of Mechanics, Chinese

Academy of Sciences, Beijing,

People's Republic of China

*These authors contributed equally to this work
Correspondence: Lei Yang; Tao Chen Department of Orthopaedic Surgery, Robotics Microsystems Center, 708 Renmin Road, Suzhou, Jiangsu 215006, People's Republic of China

Tel +86 5 I 26778 I540

Fax +86 5I26778 II65

Email ylei@suda.edu.cn; chent@suda.edu.cn
Abstract: Osteoporosis is a serious public health problem affecting hundreds of millions of aged people worldwide, with severe consequences including vertebral fractures that are associated with significant morbidity and mortality. To augment or treat osteoporotic vertebral fractures, a number of surgical approaches including minimally invasive vertebroplasty and kyphoplasty have been developed. However, these approaches face problems and difficulties with efficacy and long-term stability. Recent advances and progress in nanotechnology are opening up new opportunities to improve the surgical procedures for treating osteoporotic vertebral fractures. This article reviews the improvements enabled by new nanomaterials and focuses on new injectable biomaterials like bone cements and surgical instruments for treating vertebral fractures. This article also provides an introduction to osteoporotic vertebral fractures and current clinical treatments, along with the rationale and efficacy of utilizing nanomaterials to modify and improve biomaterials or instruments. In addition, perspectives on future trends with injectable bone cements and surgical instruments enhanced by nanotechnology are provided.

Keywords: nanomaterials, osteoporosis, vertebral fracture, kyphoplasty, bone cement, pedicle screw, radiopacifier

\section{Introduction}

Osteoporosis is a progressive bone disease characterized by reduced bone density and microarchitectural deterioration of bone tissue. ${ }^{1}$ According to the definition given by the World Health Organization, a patient is diagnosed as having osteoporosis when his/her bone mineral density is 2.5 standard deviations or more below the mean peak bone mass (defined by the average value for young healthy adults). ${ }^{2}$ For measuring bone density and evaluating osteoporosis or fracture risk prediction, dual X-ray absorptiometry is considered the "gold standard" method, ${ }^{3}$ while ultrasound methodology has been developed for population screening and diagnosis in primary care. ${ }^{4,5}$

In clinical practice, according to osteoporotic condition, osteoporosis is usually categorized as primary or secondary osteoporosis. With the increased life expectancy and rapidly aging population worldwide, osteoporosis has become a major public health problem in many countries. According to the International Osteoporosis Foundation, osteoporosis is estimated to affect one in three women and one in eight men over the age of 50 years. ${ }^{6,7}$ In the USA, it is estimated that at least 10 million people suffer from osteoporosis and over 1.5 million cases of osteoporotic vertebral fracture (OVF) occur every year, generating direct health care costs of US\$12-18 billion each year. ${ }^{8}$ In fact, the direct annual costs of treating osteoporotic fractures in the workplace in the USA, Canada, and Europe alone are estimated to be approximately $\$ 48$ billion. ${ }^{9}$ As of 2006, in the Chinese population aged 50 years or older, 65 million people were estimated to have osteoporosis, while an additional 200 million were estimated to 
have osteopenia. Demographic studies also indicate that osteoporosis may soon reach epidemic proportions in the developing world. ${ }^{10}$

One of the serious consequences of osteoporosis is an increased risk of fractures. ${ }^{11}$ Fractures can occur in many locations of the skeleton and are often associated with high morbidity and mortality. ${ }^{12}$ According to Burger's model, fractures of the spine have a much higher incidence than fractures at other sites, especially in the patient with earlier osteoporosis. Spinal or vertebral fractures are fractures in one or more vertebral bodies and are usually classified as wedge, biconcavity, or compression fractures depending on the type of deformity. ${ }^{13}$ Vertebral fractures caused by osteoporosis are also known as OVFs, which are the focus of this article. Patients experiencing a spinal fracture have an increased mortality rate of approximately $10 \%$, and female OVF patients have a $23 \%$ higher mortality rate when compared with those without OVF. ${ }^{14} \mathrm{OVF}$ is also one of the major risk factors for secondary fractures, the probability of which is increased fourfold after the first vertebral fracture occurs. ${ }^{15}$ OVF can also cause other severe physical, functional, and psychological problems or disorders, such as chronic back pain, kyphosis, and shortening of the segmental vertebrae. ${ }^{16}$ Because of the extraordinary public health challenges and economic burden imposed by OVF worldwide, prevention and treatment of OVF are of considerable importance for the health care community.

\section{Current treatments for OVF and their challenges}

Clinical treatment of OVF aims at achieving pain relief and restoring height and functional stability of the fractured vertebral body. ${ }^{17,18}$ Treatment of OVF includes non-surgical and surgical approaches, which are summarized in Table 1. Although conservative non-surgical approaches (bed rest, medication, nutritional improvements) can relieve pain and

Table I Current approaches for treating osteoporotic vertebral fractures

\begin{tabular}{ll}
\hline $\begin{array}{l}\text { Therapeutic approaches } \\
\text { Lifestyle and exercise }\end{array}$ & $\begin{array}{l}\text { Regular exercise, reduced or no } \\
\text { tobacco and alcohol } \\
\text { Calcium and vitamin D }\end{array}$ \\
$\begin{array}{l}\text { Nutritional considerations } \\
\text { Medications }\end{array}$ & Antiresorptive, anabolic agents \\
Surgical treatments & Plates and locked plates, \\
Osteoporotic fracture fixations & intramedullary nails, bone screws \\
Invasive augmentation & $\begin{array}{l}\text { Pedicle screw fixation and spinal } \\
\text { fusion, vertebral body resection } \\
\text { Vertebroplasty, kyphoplasty }\end{array}$ \\
\hline
\end{tabular}

alleviate reduce complications, they cannot restore the height and functional stability of the fractured vertebral body. Traditional surgical approaches include anterior decompression and fusion and/or posterior instrumentation and fusion, but these approaches may not be appropriate for elderly patients and still have high postoperative failure rates. ${ }^{19,20}$ Therefore, minimally invasive procedures like vertebroplasty and kyphoplasty are becoming increasingly attractive options for the treatment of OVF. ${ }^{21}$

Vertebroplasty and kyphoplasty are minimally invasive percutaneous surgical techniques that internally stabilize the vertebral body by injection of self-hardening biomaterials such as bone cements (Figure 1). Both procedures are performed using a fluorescence detector (eg, a C-arm X-ray machine) and thus require the injectable bone cement to be radiopaque. Vertebroplasty was first developed in France by Herve Deramond et al in $1986^{22}$ and was introduced to the USA in $1995 .{ }^{23}$ Vertebroplasty is effective for pain relief, and statistics show that it eases pain in $80 \%$ of patients. Vertebroplasty is also used to strengthen vertebral bodies that are weakened but not yet fractured, thereby preventing further fractures. ${ }^{24}$ However, vertebroplasty is not particularly effective in restoring the height of fractured vertebra or correcting spinal deformity. Another disadvantage of vertebroplasty is the high probability of bone cement leakages into the spinal canal, which increases the risks of neurological damage and pulmonary embolism. ${ }^{25}$

Kyphoplasty (also known as balloon-assisted vertebroplasty) was developed in the early 1990s as an improved approach to mitigate the complications of vertebroplasty and to restore the height of the fractured vertebra. ${ }^{26}$ This procedure starts with inserting an inflatable balloon catheter into the center of the fractured vertebra, after which the balloon is inflated to recover the compressed vertebral height and correct the deformity, meanwhile creating a void for injecting bone cement (Figure 1). ${ }^{27}$ Kyphoplasty is now a well established procedure for the treatment of OVF and has been practiced in many countries. ${ }^{28}$

Recently, an alternative procedure known as vertebral stenting, which is based on the principles of balloon kyphoplasty and vascular stenting, has also been developed. In vertebral stenting, after the balloon is removed, a metal stent remains within the created void to prevent the vertebral body from collapsing, so in an ideal scenario, a virtually physiological vertebral body height and shape can be restored and preserved. ${ }^{29}$ However, vertebral stenting has not been widely accepted by surgeons due to the limited supply of appropriate stents. 


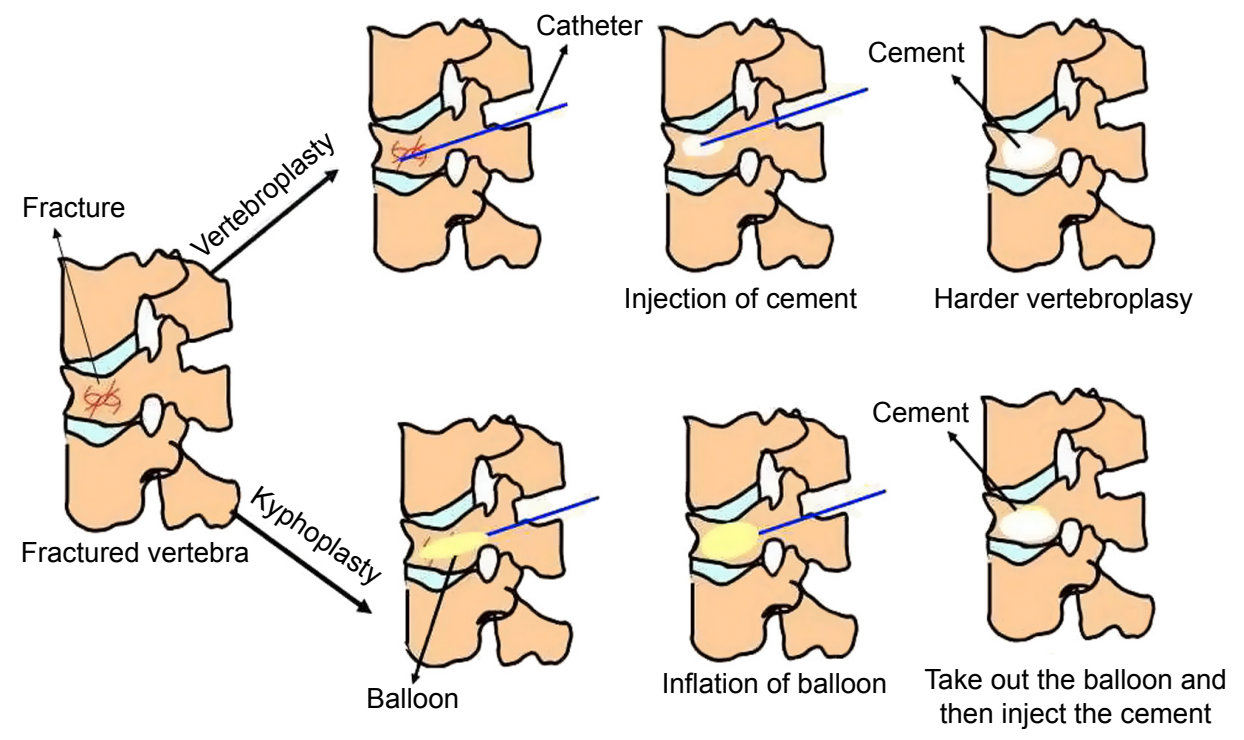

Figure I Schematic of vertebroplasty and kyphoplasty procedures, which are both minimally invasive, percutaneous surgical approaches that can internally stabilize a fractured vertebral body via injection of self-hardening biomaterials like bone cement.

Note: The difference between vertebroplasty and kyphoplasty procedures is the utilization of a balloon that is inflated to create a cavity in the compressed vertebral body prior to injection of the cement. The blue lines represent the catheter; the yellow ovals represent the balloon; and the white oval represents the cement in each instance.

Vertebroplasty and kyphoplasty or vertebral stenting face a number of problems in clinical practice, including those associated with bone cement, which will be further discussed. In addition, bacterial infection is a common complication associated with implants or devices for the treatment of OVF. Although minimally invasive surgery can significantly lower the risk of infection when compared with open surgery, bacterial colonization and formation of biofilm on the implanted device cannot be completely eradicated. The consequences of infection are severe, leading to considerable health care burden, prolonged patient suffering, and substantial morbidity and even mortality ${ }^{30}$ As a result, reducing infection in the surgical treatment of OVF has also become a persistent challenge.

\section{Nanotechnology for orthopedic applications}

Bone is a natural nanocomposite that consists of hierarchically arranged collagen fibrils, proteoglycans, and hydroxyapatite (HA) crystals, all at nanometer scale. Inspired by this nanostructure, it has been widely speculated that mimicking nanoscale features of natural bone in materials or creating topographies resembling nanoscale roughness of bone may enhance new bone growth or regeneration. This strategy provides innovative opportunities to design and fabricate novel material formulations, devices, and systems, or to modify existing ones for better outcomes. Based on a similar rationale, nanotechnology-based bone tissue engineering, which combines living cells and growth factors with appropriate biomaterial nanoscaffolds for restoration and regeneration of defective bone tissue, has also been developed. ${ }^{31}$ Moreover, nanotechnology has demonstrated significant impacts on the development of novel bone substitutes, biological electronics such as biosensors, sensitive diagnostic systems, and controlled drug delivery systems. ${ }^{32}$

Recent studies have shed light on the mechanism(s) behind the positive role of nanotechnology in orthopedic applications. On the one hand, this positive role is attributed to the factors such as vastly changed grain (or feature) size, surface roughness and surface area-to-volume ratio, surface wettability, and associated energetics, which have also been correlated with the superior physiochemical properties of nanomaterials, including their mechanical, electrical, optical, catalytic, and magnetic properties. ${ }^{33}$ On the other hand, studies have arguably elucidated that favorable cell or tissue responses to nanomaterials are strongly correlated with greater adsorption or interactions of selected proteins compared with conventional micron-sized materials. This may be one of the underlying mechanisms accounting for why nanomaterials possess more intriguing biological properties than conventional micron-sized materials. ${ }^{33}$

Increasing numbers of nanotechnologies and nanomaterials have been developed and are utilized in the field of orthopedics, and there is a growing interest in the research and development of nanotechnology for preventing and treating osteoporosis. For instance, nanotechnology has been utilized to enhance the bioavailability of calcium supplements, which can reduce the risk of developing 
osteoporosis. Nano calcium carbonate and calcium citrate were devised and prepared to increase bioavailability in the gastrointestinal tract. ${ }^{34}$ The results suggested that nanosized calcium carbonate and calcium citrate are more bioavailable than orally administered microsized calcium carbonate and calcium citrate, respectively.

The present article addresses the frontiers of research on nanotechnology and nanomaterials tentatively used for treating OVF. New advances in injectable nanomaterials and surgical tools for vertebroplasty and kyphoplasty, such as improvements in the mechanical, biocompatible, antibacterial, and radiological properties of bone cements and tools, are also analyzed. However, since the nanotechnologies and nanomaterials for treatment of OVF are still in the early stages of development, most studies to date have been performed in vitro, and the efficacy and feasibility of these nanotechnologies and nanomaterials for clinical use have not been explicitly demonstrated. Therefore, this review focuses more on the potential and promise of nanotechnology and nanomaterials for treating OVF and future perspectives.

\section{Injectable nanomaterials for treatment of OVF}

Surgical procedures for treating OVF essentially aim at regaining sufficient strength and height of the fractured vertebral body with the assistance of implants and/or biomaterials. ${ }^{35}$ Possible implants and biomaterials include metal fixtures (eg, screws, plates, rods) and bone fillers that can augment osteoporotic or weak vertebral bodies. In the aforementioned minimally invasive procedures like vertebroplasty and kyphoplasty, bone fillers need to be injectable and then able to solidify, so are also known as bone cements. ${ }^{35}$ So far, the only clinically approved bone cement is polymethylmethacrylate (PMMA) cement, ${ }^{36}$ and others currently under development include calcium phosphate cement (CPC) $)^{37}$ and calcium sulfate cement (CSC).$^{38}$ Meanwhile, new radiopacifiers for imaging purposes during minimally invasive surgery have also been developed. In addition, injectable hydrogel is a new candidate for bone healing and regeneration via minimally invasive procedures. In this section, current progress and advances with these three injectable materials are summarized.

\section{Bone cements}

A package of bone cement usually consists of a powder component and a liquid phase acting as a reaction medium. During surgery, bone cement is formed into a paste by mixing the powder and the liquid, and the paste can then either be injected through a channel or molded by the surgeon into the sites of bone defects or voids. ${ }^{39}$ After setting and hardening, the paste conforms to the shape of the defect or void, and solidifies to achieve enough strength to support the vertebra. The characteristics and properties of PMMA, CPC, and CSC for vertebroplasty and kyphoplasty are shown in Table 2 .

An ideal bone cement for vertebroplasty and kyphoplasty is expected to have the following properties: high injectability and homogeneity during injection; appropriate setting properties allowing appropriate handling times; high biocompatibility and low risk of necrosis or infection; adequate mechanical strength and appropriate stiffness to match neighboring vertebral bodies; bioactivity and bioresorbability to stimulate new bone ingrowth or appropriate porous structures for osseointegration and angiogenesis; and high radiopacity for tracking during surgery. In order to achieve these goals, nanotechnology has recently been applied to improve the properties of various bone cements.

\section{Polymethylmethacrylate cement}

PMMA bone cement has excellent setting and injectability as well as adequate mechanical properties for augmentation of a fractured vertebral body (Table 2). ${ }^{40}$ However, PMMA bone cements have clear disadvantages, including monomer toxicity, high polymerization temperature detrimental to tissue, a lack of biological potential to remodel or integrate into bone, and excessive stiffness that may cause fracture at the adjacent levels. ${ }^{41}$ Among these problems, the lack of capability for osseointegration and excessive stiffness are intrinsic drawbacks that cannot be avoided by carefully adjusting the surgical procedure. ${ }^{42}$

Nanotechnology has recently opened up new opportunities to resolve these problems. For improving osseointegration,

Table 2 Properties of PMMA, CPC, and CSC bone cements

\begin{tabular}{|c|c|c|c|c|c|c|c|}
\hline Cement & Wettability & Injectability & $\begin{array}{l}\text { Setting } \\
\text { time }\end{array}$ & $\begin{array}{l}\text { Thermal } \\
\text { effects }\end{array}$ & $\begin{array}{l}\text { Compressive } \\
\text { strength (MPa) }\end{array}$ & $\begin{array}{l}\text { Tensile strength } \\
\text { (MPa) }\end{array}$ & Biodegradability \\
\hline PMMA & Hydrophobic & Excellent & $\sim 20$ minutes & Exothermic & $>70$ & $>50$ & Not degradable \\
\hline CPC & Hydrophilic & Critical & $\sim 20$ minutes & Isothermal & $<25$ & $<15$ & Low \\
\hline CSC & Hydrophilic & Good & $\sim 10$ minutes & Isothermal & $<4 I$ & $<15$ & High \\
\hline
\end{tabular}

Abbreviations: PMMA, polymethylmethacrylate; CPC, calcium phosphate cement; CSC, calcium sulfate cement. 
nanomaterials with unique topography, surface roughness, surface hydrophilicity, and surface energy properties have shown a strong ability to mediate specific protein adsorption and subsequent cell behavior and tissue regeneration. ${ }^{33}$ This rationale has been applied to modify PMMA bone cement by incorporating nanoparticles, nanofibers, and other nanostructures for introducing enhanced osseointegrative capability to bio-inert PMMA. For example, a number of studies have shown improved bone cell activity on PMMA which was modified with nanostructured additives even if the additives were not inherently bioactive. Ricker et $\mathrm{al}^{43}$ reported PMMA bone cements with nanophase $\mathrm{MgO}$ and $\mathrm{BaSO}_{4}$ had higher osteoblast adhesion densities than pure PMMA cement samples after 4 hours of culture, as shown in Figure 2. Also, the effect of incorporating $10 \mathrm{wt} \% \mathrm{MgO}$ nanoparticles (12.8 nm in size) into PMMA on increasing surface roughness of the cement was investigated. The results showed that the bone cement with nanophase $\mathrm{MgO}$ significantly increased surface roughness when compared with PMMA modified with the same amount of microparticles. ${ }^{43}$ Similarly, the increased nanometer surface roughness achieved by embedding $\mathrm{TiO}_{2}$ nanoparticles (32 $\mathrm{nm}$ in diameter) in polymer matrix was demonstrated to increase osteoblast activity. ${ }^{39}$ Based on these in vitro studies, it appears that the improved osteoblast activity of PMMA bone cements are due to the nanoscale surface roughness resulted from addition of oxide nanoparticles.

The ultrahigh stiffness of PMMA bone cement, which reaches 2-3 GPa (elastic modulus) and is 4-40 times higher than that of human cancellous bone (50-800 MPa depending on location), is another impediment to its application in treating OVF. This high stiffness has a stress-shielding effect, weakening neighboring vertebrae and ultimately causing them to fracture. ${ }^{39}$ Creating porous structures in the hardened PMMA bone cement is becoming an effective strategy to overcome the ultrahigh stiffness of PMMA. For example, the elastic modulus and yield strength of PMMA could be decreased when mixed with a $2 \%$ aqueous solution of sodium hyaluronate gel. ${ }^{44}$

In order to develop bone cement with anti-infective properties, silver nanoparticles has been investigated as a antimicrobial additive to bone cement. Alt et al showed that PMMA bone cement loaded with $1 \mathrm{wt} \%$ nanosilver (particle sizes of 5-50 $\mathrm{nm}$ ) had satisfactory antibacterial activity against all bacterial strains tested, including $S$. epidermidis and methicillin-resistant strains of both $S$. epidermidis and $S$. aureus. Among three different concentrations of nanosilver $(0.1,0.5$, and $1 \mathrm{wt} \%)$, PMMA with $1 \mathrm{wt} \%$ nanosilver exhibited the highest antibacterial activity, with no decrease in human osteoblast viability when
Pure PMMA

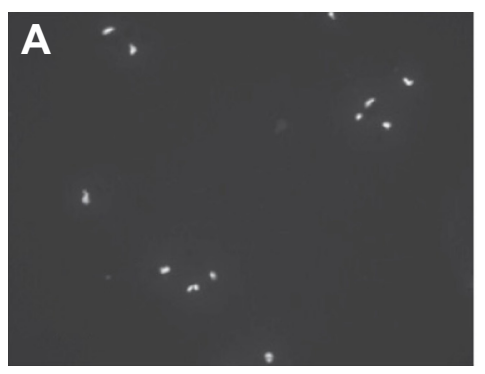

Conventional MgO

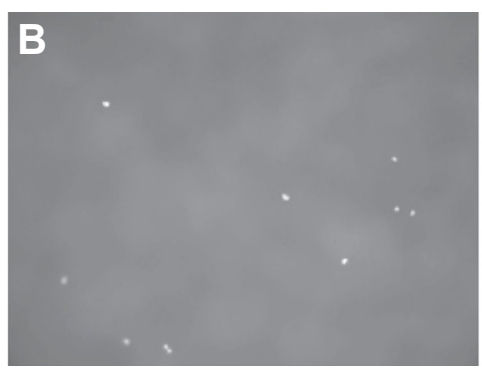

Nano MgO

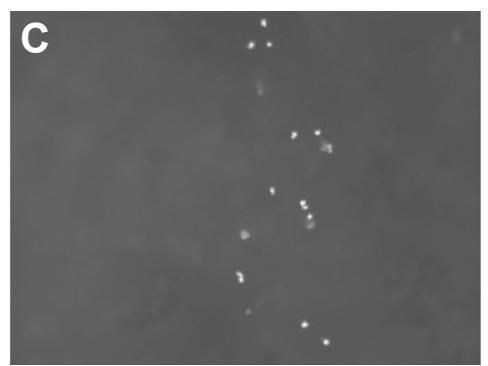

Conventional $\mathrm{BaSO}_{4}$

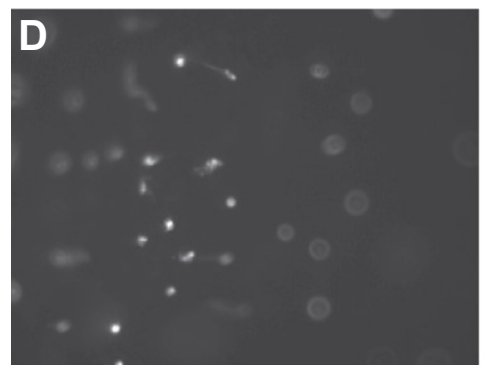

$\mathrm{Nano} \mathrm{BaSO}_{4}$

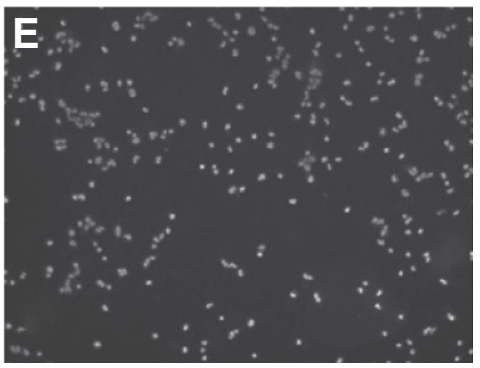

Figure 2 Fluorescent images showing osteoblast adhesion (nuclei stained with DAPI) on PMMA modified with nano and conventional $\mathrm{MgO}$ and $\mathrm{BaSO}_{4}$ (magnification $100 \times$ ). (A) Pure PMMA; (B) conventional $\mathrm{MgO}$; (C) nano $\mathrm{MgO}$; (D) conventional $\mathrm{BaSO}_{4}$; and (E) nano $\mathrm{BaSO}_{4}$.

Notes: Osteoblast adhesion was significantly increased on nanoparticle-modified PMMA compared with pure PMMA or PMMA modified with conventional particles. Copyright (2008. Dove Medical Press. Reproduced from Ricker A, Liu-Snyder P, Webster TJ. The influence of nano $\mathrm{MgO}$ and BaSO ${ }_{4}$ particle size additives on properties of PMMA bone cement. Int J Nanomedicine. 2008;3:125-132.43

Abbreviations: PMMA, polymethylacrylate; DAPI, 4,6-diamidino-2-phenylindole. 
compared with osteoblasts cultured without adding silver. ${ }^{45}$ This suggests that PMMA incorporated with nanosilver may be a promising bone cement for clinical use due to it high antibacterial activity and lack of cytotoxicity.

\section{Calcium phosphate cement}

As an alternative to PMMA bone cement, CPCs have received much attention due to their chemical similarity to natural bone, high bioactivity and biodegradability, and the isothermal reaction during setting. ${ }^{37}$ Usually, CPC consists of one or more calcium phosphate compounds (such as $\mathrm{CaHPO}_{4}$, $\left.\mathrm{Ca}_{8} \mathrm{H}_{2}\left(\mathrm{PO}_{4}\right)_{6} \cdot 5 \mathrm{H}_{2} \mathrm{O}\right)$ and a liquid phase of water or phosphatecontaining aqueous solution. Depending on the composition of the final product, CPCs are usually classified into brushite (dicalcium phosphate dihydrate) CPC or apatite CPC. Firstly developed by Brown and Chow in 1986, the attempt to use CPC for augmentation of osteoporotic bone started in $1992^{46}$ and use of CPC for intravertebral reconstruction was proposed in $1995 .{ }^{47}$ In the last two decades, CPC has also been investigated for its ability to reinforce osteoporotic vertebral bodies, ${ }^{48}$ thoracolumbar burst fractures, ${ }^{49}$ and pedicle screw fixation. ${ }^{50}$ However, most of the commercially available CPC products are not suitable for treating OVF or replacing load-bearing bones due to insufficient mechanical properties, setting and hardening times that are too long, and uncontrolled degradation.

In order to tackle these problems, nanotechnologyenhanced CPCs have been developed by a number of companies and research groups (Table 3$).{ }^{51-53}$ Some of the CPCs are based on strategies of decreasing the particle size of the starting calcium phosphate compounds to a nanometer or submicron range or adding nanophase materials to existing CPC systems. Alpha- and beta-tricalcium phosphates with reduced particle sizes could substantially decrease setting time, facilitate nucleation of apatite crystals, and accelerate hardening of the cement without significantly affecting the final compressive strength $(41 \pm 1.8 \mathrm{MPa}) .{ }^{54}$ In addition to the strategy of reducing particle size, ultrafine nanofibers prepared by electrospinning were also incorporated into $\mathrm{CPC}$ and the results showed clear increases in the fracture resistance of CPC. This CPC-nanofiber composite had an elastic modulus (15-50 GPa) comparable with that of human cortical bone, and degradation of the fibers could introduce pores and interconnective channels for bone ingrowth. ${ }^{55}$

Although adding nanofibers has a positive effect by enhancing the mechanical properties of CPC, identification of suitable nanofibers that are bioresorbable and bioactive while being able to provide sufficient strength and fracture toughness remains challenging. ${ }^{39}$ Recent studies have demonstrated that carbon nanotubes (CNTs) may be a reasonable choice. In the study by Wang et al, incorporation of $0.2 \mathrm{wt} \%$ and $0.5 \mathrm{wt} \%$ as-received CNTs into CPC resulted in an increase in compressive strength by $24 \%$, and biomineralized CNTs led to a $120 \%$ increase in the compressive strength of CPC. ${ }^{56}$ Similarly, Chew et a ${ }^{57}$ reported a high-strength CPC achieved by reinforcement of multi-walled CNTs and bovine serum albumin. This CPC/multi-walled CNT/bovine serum albumin composite had substantially improved compressive strength $(\sim 16 \mathrm{MPa})$ compared with pure CPC cement $(\sim 1 \mathrm{MPa})$. Their study also suggested that hydroxyl functional groups on the surface of multi-walled CNTs improved their reactivity and wettability, leading to strong interfacial bonding with CPC. In addition, strong attractions of $\mathrm{Ca}^{2+}$ and $\mathrm{PO}_{3}{ }^{4-}$ ions with the functional groups of multi-walled CNTs-OH are expected to promote nucleation and growth of HA crystals in the bone cement, enhancing mechanical strength and osteoconductivity. Further, adding $5 \mathrm{wt} \% \mathrm{CaSiO}_{3}$ nanofibers (with an aspect ratio of 9.6) achieved a significant $250 \%$ increase in the compressive strength of CPC (from 14.5 to $50.4 \mathrm{MPa}$ ) but no decrease in self-setting ability of the cement. Better than CNTs or other nanofibers, $\mathrm{CaSiO}_{3}$ can simultaneously release $\mathrm{Ca}$ and $\mathrm{Si}$ ions during hydrolysis, and the increases in $\mathrm{Ca}$ ion concentration and silica gel precipitation can

Table 3 Nanotechnology-enabled calcium phosphate cements

\begin{tabular}{|c|c|c|c|c|c|}
\hline $\begin{array}{l}\text { Commercial } \\
\text { name }\end{array}$ & Components & Setting time & $\begin{array}{l}\text { End } \\
\text { product }\end{array}$ & $\begin{array}{l}\text { Compressive } \\
\text { strength }(\mathrm{MPa})\end{array}$ & $\begin{array}{l}\text { Companyl } \\
\text { references }\end{array}$ \\
\hline Biopex & $\begin{array}{l}70 \% \alpha-\mathrm{TCP}, 23 \% \text { TTCP, } 5 \% \text { DCPA, } \\
2 \% \mathrm{HA}\end{array}$ & $7-10$ minutes & Apatite & 80 & Mitsubishi \\
\hline$\alpha$-BSM & ACP, DCPD & 15-20 minutes & Apatite & 4 & ETEX \\
\hline- & $\beta-T C P, D C P A, M W C N T / B S A$ & $\sim 20$ minutes & Brushite & 13.65 & Low et $\mathrm{al}^{51}$ \\
\hline- & $\alpha-\mathrm{TCP}, 2$ wt\% HA, $0.1 \%$ Fe nanoparticles & $\sim 13$ minutes & Apatite & 33 & Perez et al ${ }^{52}$ \\
\hline- & $\begin{array}{l}\alpha-\mathrm{TCP}, 2 \mathrm{wt} \% \mathrm{HA}, 10 \mathrm{wt} \% \text { mesoporous } \\
\text { bioglass nanoparticles }\end{array}$ & $\sim 25$ minutes & Apatite & 26 & El-Fiqi et al ${ }^{53}$ \\
\hline
\end{tabular}

Abbreviations: $\alpha$-TCP, alpha-tricalcium phosphate; $\beta$-TCP, beta-tricalcium phosphate; DCPA, dicalcium phosphate; $\mathrm{HA}$, hydroxyapatite; $\mathrm{ACP}$, amorphous calcium phosphate; DCPD, dicalcium phosphate dehydrate; MWCNT, multiwalled carbon nanotubes; BSA, bovine serum albumin; TTCP, tetracalcium phosphate. 
facilitate precipitation of HA crystals in the cement setting reaction. This $\mathrm{CaSiO}_{3}$ nanofiber-based strategy of enhancing the mechanical properties of CPC is still under development but can potentially be used for the treatment of OVF.

\section{Calcium sulfate cement}

Calcium sulfate, also known as plaster of Paris or gypsum, has a long clinical history as a bone graft substitute. ${ }^{58}$ Surgical-grade CSC is mainly calcium sulfate hemihydrate $\left(2 \mathrm{CaSO}_{4} \cdot \mathrm{H}_{2} \mathrm{O}, \mathrm{CSH}\right)$, the physical properties of which are shown in Table 2. Compared with CPC, CSC has relatively higher mechanical strength but degrades much faster. Studies show that it may be fully absorbed within a few weeks after implantation in vivo. ${ }^{59}$ For application in the treatment of OVF, this fast degradation rate generates problems with regard to insufficient mechanical stability and mismatch between bone remodeling and cement receding.

Incorporation of nanostructured materials has been shown to be an effective strategy to improve the mechanical properties of CSC. The influence of ceramic nanoparticles on the hydration reaction and consequent mechanical properties of the CSC cement was investigated. ${ }^{60}$ The results showed that a compressive strength as high as $72 \mathrm{MPa}$ was achieved after 42 days for the $\mathrm{CSC}$ doped with $10 \mathrm{wt} \%$ of electric arc furnace dust, which was mainly composed of $\mathrm{ZnFe}_{2} \mathrm{O}_{4}$ nanoparticles. Another study of a nanocomposite cement containing $\mathrm{CSH}$ and biomimetic nanocrystalline carbonated apatite revealed that initial setting time and injectability of the nanocomposite increased to 33 minutes and 95\% compared with 7 minutes and $71 \%$ for pure $\mathrm{CSH}$, respectively. ${ }^{61}$ To control the degradation rate of CSC, Liu et al studied degradation of a nanocrystalline $\mathrm{HA} / \mathrm{CSH}$ composite and showed that addition of $30 \mathrm{wt} \% \mathrm{HA}$ nanocrystals to $\mathrm{CSH}$ had a significant effect on the degradation rate of the composite cement. ${ }^{62}$

\section{Other bone cements}

Other types of injectable bone cements, including calcium silicate cement (CSiC), magnesium phosphate cement, and bioactive glass cement, have also received attention. CSiC is primarily used for replacement of dentine, but there is a highly basic calcium hydroxide byproduct that is potential toxic to osteogenic activity and bone regeneration. Some nanoparticles are used to reduce generation of this calcium hydroxide byproduct while also improving the mechanical properties of CSiC. For example, CSiC/Nano- $\mathrm{Fe}_{2} \mathrm{O}_{3}$ and $\mathrm{CSiC} / \mathrm{Nano}-\mathrm{SiO}_{2}$ composites have been developed, ${ }^{63}$ and the compressive and flexural strengths of the $\mathrm{CSiC}$ cements containing nano- $\mathrm{SiO}_{2}$ and nano- $\mathrm{Fe}_{2} \mathrm{O}_{3}$ were both higher than those of the CSiC cement. Scanning electron microscopy (SEM) revealed that the nanoparticles acted not only as fillers but also as activators promoting hydration of the cement. Moreover, blended CSiC were fabricated by adding CNTs and nanoclay (kaolin clay) to the cement, and the nanoclay was found to improve CNT dispersion and interfacial interaction between cement phases. For example, replacement of $\mathrm{CSiC}$ by $6 \mathrm{wt} \%$ exfoliated nanoclay increased compressive strength by $18 \%$, and combination of $6 \mathrm{wt} \%$ nanoclay and $0.02 \mathrm{wt} \%$ CNTs increased the compressive strength by $29 \%$, all compared with unmodified CSiC cement.

In summary, combining nanomaterials with bone cement to create nanocomposite has showed great potential for improving the mechanical properties of bone cement in the treatment of OVF. ${ }^{39}$ This strategy also has the ability to provide a bioactive environment for enhancing bone cell recruitment, adhesion, proliferation, and differentiation. ${ }^{39}$ Therefore, nanotechnology-enhanced bone cements are expected to be better for the treatment of OVF and thus should be further studied and developed.

\section{Injectable hydrogels}

Because of their biomimetic structure similar to that of extracellular matrix, a number of hydrogels have been developed as injectable carriers of growth factors, drugs, or cells for bone repair or regeneration. Unlike the aforementioned injectable bone cements, injectable hydrogel has in situ cross-linking ability that can be initiated by temperature, $\mathrm{pH}$, light, or ions. For example, a thermosensitive injectable hydrogel for long-term sustained and controlled drug delivery was created by adding biodegradable poly(3hydroxybutyrate-co-3-hydroxyhexanoate) nanoparticles to chitosan. ${ }^{64}$ Abdel-Bar et al developed an injectable and thermoreversible chitosan/ $\beta$-glycerophosphate hydrogel system that enabled controlled release of vancomycin for the treatment of orthopedic infections. ${ }^{65}$ Many hydrogels contain rich carboxylic groups that can chelate with calcium-containing phosphates, thus facilitating the formation of polymer/ calcium phosphate composites resembling natural bone.

However, hydrogels alone are generally too soft to be applied for the repair or treatment of load-bearing bones like the spine. Incorporating nanoscale components into the hydrogel system is an effective approach to reinforce hydrogel and combine new functionalities. Campbell et al devised an injectable composite hydrogel of poly ( $N$-isopropylacrylamide) reinforced by superparamagnetic iron oxide nanoparticles, which showed extremely high elasticity $\left(\mathrm{G}^{\prime}>60 \mathrm{kPa}\right)$ and contrast for magnetic resonance imaging 
purposes. ${ }^{66}$ Silk fibroin hydrogel containing HA nanoparticles (silk fibroin/HA composite hydrogel) is another promising injectable hydrogel developed for bone regeneration and repair. ${ }^{67}$ Similarly, a variety of gelatin-based hydrogels modified by nanoparticles have been developed. ${ }^{68,69}$ For example, a composite hydrogel of photopolymerizable gelatin incorporating recombinant bone morphogenetic protein (BMP)-2 and sulfated chitosan nanoparticles was prepared and shown to have clear advantages for sustained and sequential delivery of growth factors (eg, BMP-2 and BMP-7). ${ }^{68}$ Biodegradable gelatin hydrogel incorporating gold nanoparticles (average size $27 \pm 3 \mathrm{~nm}$ ) was also studied. ${ }^{70}$ The results showed that these gel-gold nanoparticles were degradable with collagenase and promoted significant alkaline phosphatase activity, proliferation, viability, and osteogenic differentiation of stem cells. Moreover, the gel-gold nanoparticles achieved significantly greater new bone formation in vivo, indicating its potential for treating fractured bones.

Although nanoparticle-modified hydrogels demonstrate great potential for delivering drugs to treat diseases of bone, use of hydrogels in the treatment of OVF remains challenging.
A temporary fixation strategy was developed recently in order to expand the application of hydrogels to load-bearing bones like spine, as shown in Figure 3. Specifically, a delivery system consisting of an electrospun polycaprolactone nanofibrous mesh tube was used to support alginate hydrogel until sufficient bone regeneration was achieved (Figure 3). ${ }^{71}$ The main advantages of the nanofibrous mesh tube were that it could support cell infiltration and bone formation while acting as a barrier to separate the osseous and nonosseous regions. Local delivery of BMP-2 via the hydrogel was tested, and the results showed that the BMP-2 delivery system could effectively repair large bone defects (Figure 3D-G).

\section{Nanoparticles for localized drug delivery and treatment}

Targeting of systemically administered drug conjugates and particles to bone is an attractive and minimally invasive option for treatment of osteoporosis and its complications. However, drug conjugates may suffer from instability of the active components during delivery to the site of action or at the site of action. ${ }^{72}$ Therefore, a localized and controlled
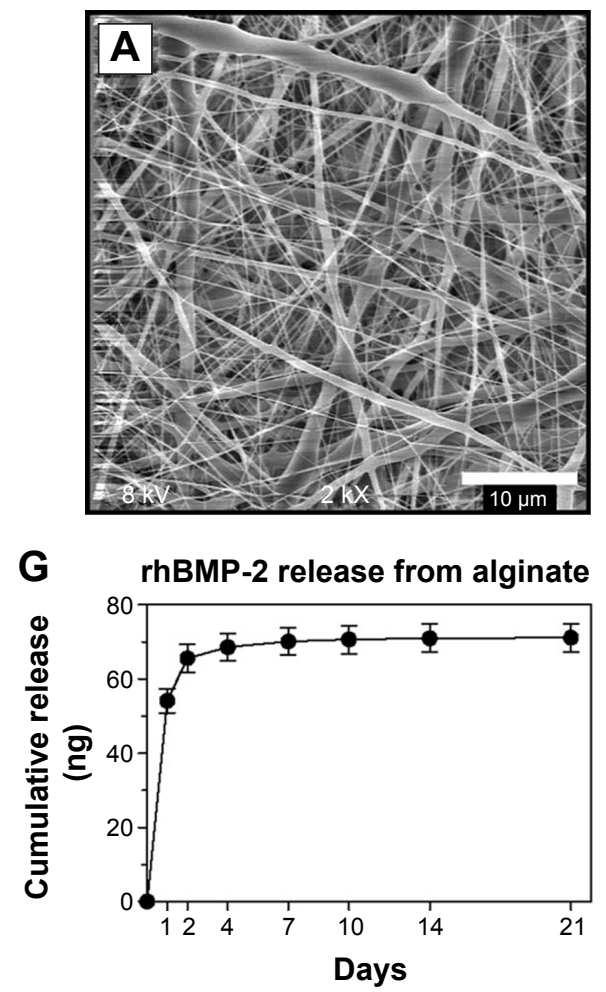
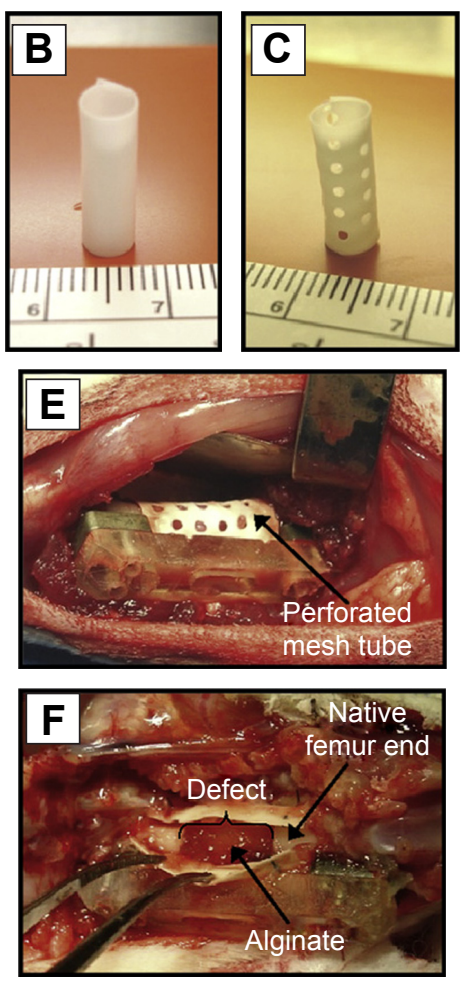

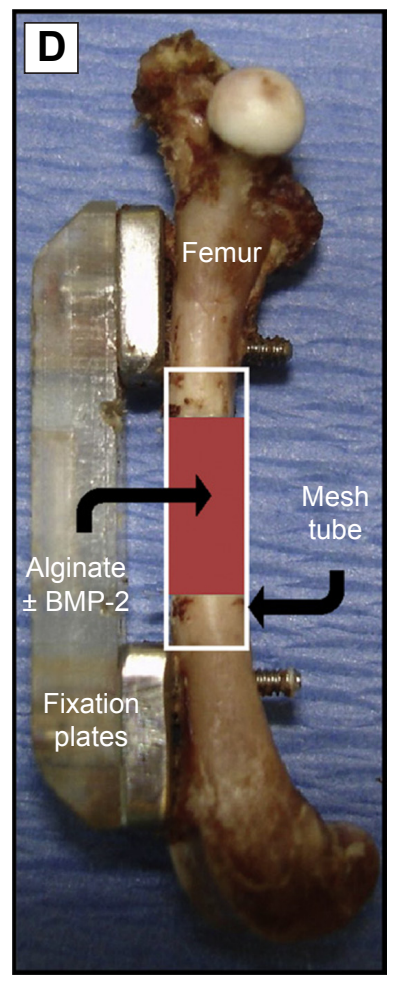

Figure 3 An alginate-based hybrid system consisting of electrospun nanofibrous mesh for growth factor delivery and bone repair.

Notes: (A) Scanning electron micrograph of electrospun nanofibrous mesh illustrating the smooth and bead-free nanofibers. Tubular bone implants made from nanofibrous mesh (B) without and (C) with perforations. (D) Scheme of mesh tube implant in segmental bone defect, where modular fixation plates are used to stabilize the bone and a nanofibrous mesh tube is placed in a defect $8 \mathrm{~mm}$ long. Also, alginate hydrogel with or without rhBMP-2 may be injected into the hollow tube. (E) Photograph of the surgical site after placing a perforated mesh tube. (F) The mesh tube was retrieved I week after implantation and the mesh tube was cut open, where the alginate was still present inside the defect. (G) Curve showing release kinetics of rhBMP-2 from alginate over 2 I days in vitro, and sustained release of the rhBMP-2 was observed during the Ist week. Reproduced from Biomaterials. Vol 32. Kolambkar YM, Dupont KM, Boerckel JD. An alginate-based hybrid system for growth factor delivery in the functional repair of large bone defects. 65-74. 201I, with permission from Elsevier. ${ }^{71}$

Abbreviation: rhBMP, recombinant human bone morphogenetic protein-2. 
drug delivery system for OVF patients would be an attractive strategy for the enhancement of bone-implant integration during or after surgery. Nanotechnology also provides new ways to enable or enhance local treatment of OVF, and a number of examples are listed in Table 4. ${ }^{72-77}$ Specifically, a novel biodegradable thermosensitive drug carrier based on amphiphilic monomethoxypoly (ethylene glycol)-copoly(lactic-co-glycolic acid) (mPEG-PLGA) diblock copolymers has been developed for treating osteomyelitis. ${ }^{76}$ The prepared mPEG-PLGA hydrogels were useful for formulation of injectable drug depots, and an in vivo study confirmed sustained release of teicoplanin from mPEG-PLGA hydrogel, which could efficiently treat osteomyelitis in rabbits and avoid the disadvantages of PMMA cement beads.

In addition, bisphosphonate-loaded calcium phosphate nanoparticles ( $\mathrm{nCaPs}$ ) have been prepared for treating problems associated with osteoporosis. ${ }^{78}$ The peri-implant bone response to titanium implants coated with bisphosphonate-loaded nCaPs was evaluated in an established rat femoral condyle implantation model of osteoporotic and healthy bone under compromised medical conditions. The results demonstrated that combined use of $\mathrm{nCaPs}$ and bisphosphonates increased both bone formation and boneto-implant contact, and also suggested that simultaneous targeting of bone formation (by $\mathrm{nCaPs}$ ) and bone resorption (by bisphosphonates) represents an effective strategy for improving bone-implant integration, especially in the case of osteoporotic patients.

\section{Nanostructured radiopacifiers}

Since bone cement materials are not usually visible under $\mathrm{X}$-ray radiation, adding radiopacifier becomes necessary to enable monitoring and tracking of bone cement during minimally invasive surgeries like vertebroplasty and kyphoplasty. Micron-sized $\mathrm{BaSO}_{4}$ and zirconium dioxide $\left(\mathrm{ZrO}_{2}\right)$ particles have been used as radiopacifiers in bone cements for years. ${ }^{79}$ However, the evidence shows that adding high contents of micron-sized $\mathrm{BaSO}_{4}$ or $\mathrm{ZrO}_{2}$ is detrimental to the mechanical and biological properties of bone cement. For example, addition of micron-sized $\mathrm{BaSO}_{4}$ particles decreased the tensile strength of PMMA bone cement from $45 \mathrm{MPa}$ to $36 \mathrm{MPa}$, since agglomerates of $\mathrm{BaSO}_{4}$ could serve as initiation sites for fatigue cracks. ${ }^{43}$ Based on the reinforcing strategy mentioned in the previous sections, there is a

Table 4 Nanotechnology-enabled local treatments of osteoporotic vertebral fracture (OVF) or osteoporosis

\begin{tabular}{ll}
\hline System & Properties and functions for local treatments \\
\hline Gelatin hydrogels incorporated with & - Biodegradable by collagenase \\
gold nanoparticles (mean size $\sim 27 \pm 3 \mathrm{~nm}$ ) & - Ability to promote proliferation, differentiation, and alkaline phosphate \\
& activities of human adipose-derived stem cells in vitro \\
& - Ability to significantly affect new bone formation in vivo \\
Alginate microencapsulation & - Extended release of drugs throughout time \\
of chitosan-dextran sulfate-bovine serum & - Improved protection and transport of the biomolecules and cells \\
albumin nanoparticles and mesenchymal & into the target injured tissue
\end{tabular}

stem cells (dual delivery system)

Tigecycline-loaded calcium-phosphate/ poly(D,L-lactide-co-glycolide) nanoparticles

- Prolonged release of antibiotic in the first 20 days

- Very low level of in vitro cytotoxicity

- Lowest content of tigecycline proved to be suitable for local and controlled delivery of the antibiotic in vivo

RNA interfering molecules from in situ forming hydrogels

- Sustained and controlled release of RNA interfering molecules over the course of 3-6 weeks

- Maintained high bioactivity of the molecules after release

- Prolonged delivery of small interfering RNA and/or micro RNA permitted extended regulation of cell behavior

Teicoplanin-encapsulated monomethoxy poly(ethylene glycol)-poly-D,L-lactide-coglycolide hydrogel nanoparticles

- Temperature-responsive hydrogel useful for the formulation of injectable drug depots

- Sustained release of teicoplanin for efficient treatment of osteomyelitis in rabbits without the disadvantages of polymethylmethacrylate cement beads

Bisphosphonate-loaded calcium phosphate nanoparticle-coated on

- Increased bone formation and bone-to-implant contact 77 titanium implants

- Simultaneous targeting of bone formation (by calcium phosphate nanoparticles) and bone resorption (by bisphosphonate) by bisphosphonate-loaded calcium phosphate nanoparticle surface coatings

- Effective for synergistic improvement of bone-implant integration, especially in osteoporotic conditions 
growing interest in developing a nanosized radiopacifier with high X-ray contrast which can promote the mechanical strengths and biological properties of the bone cement at the same time. For instance, when compared with conventional $\mathrm{BaSO}_{4}$ microparticles, addition of $10 \mathrm{wt} \% \mathrm{BaSO}_{4}$ nanoparticles into commercial PMMA cement resulted in

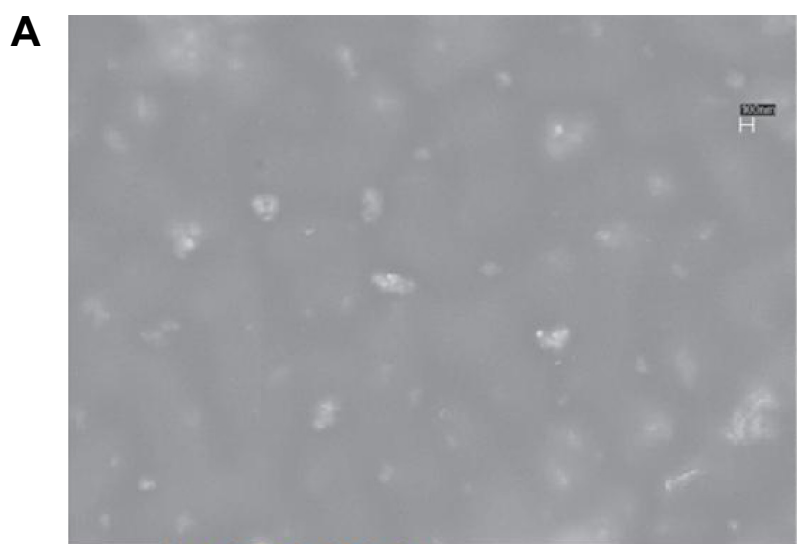

B
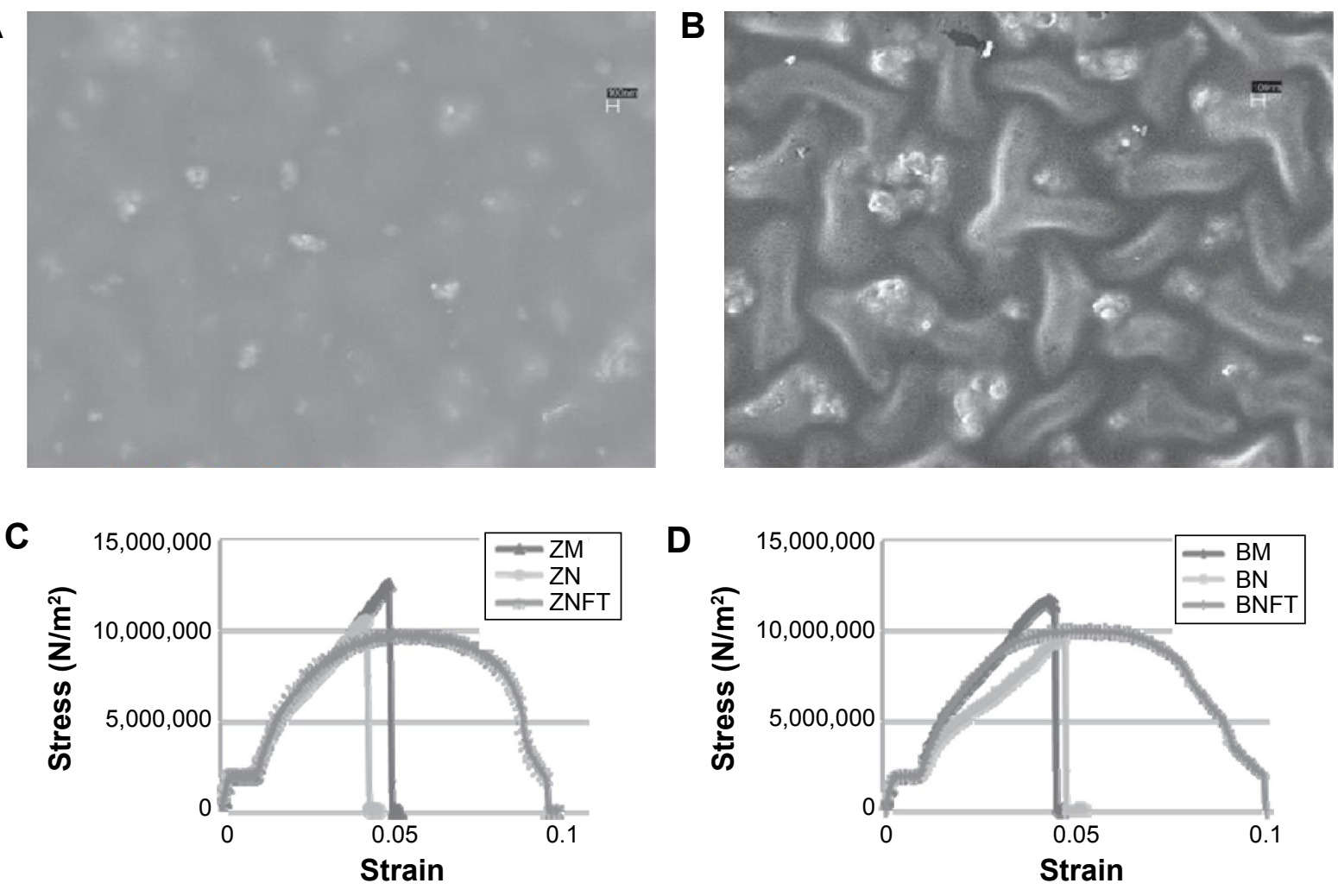

a $41 \%$ increase in tensile strain-to-failure, a $70 \%$ increase in tensile work-of-fracture, and a twofold increase in the fatigue life of the cement (Figure 4) ${ }^{80}$ Similar results has been found for bone cements containing $\mathrm{ZrO}_{2}$ nanoparticles (Figure 4). Furthermore, a study by Ajeesh et $\mathrm{al}^{81}$ showed improved osteoblast adhesion and proliferation on PMMA

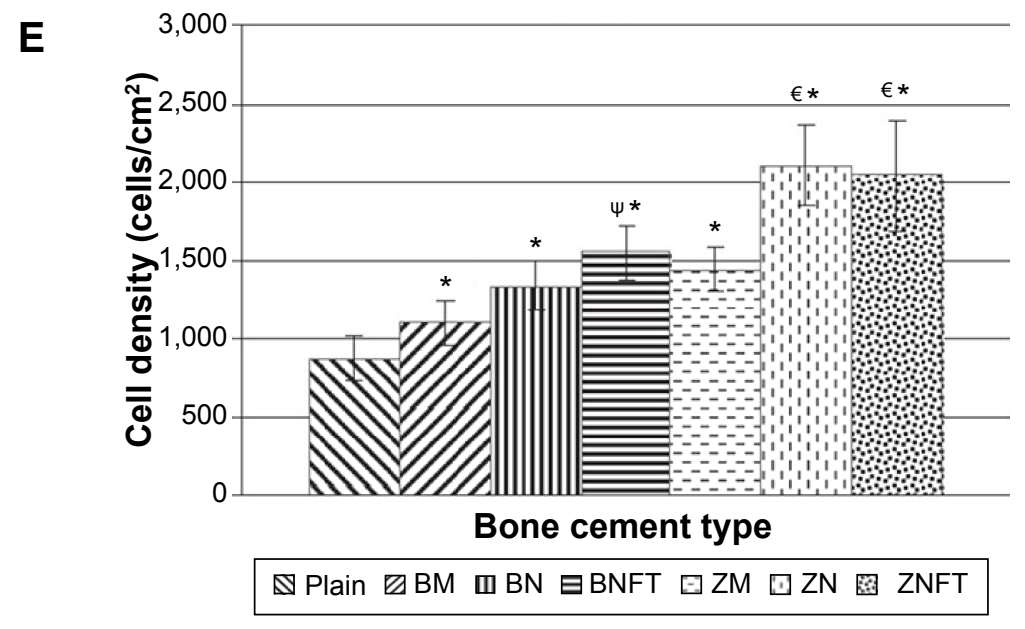

Figure 4 Morphology, mechanical properties and biocompatibility of bone cements containing functionalized nanoparticles.

Notes: Scanning electron micrographs of (A) ZNFT bone cement containing functionalized $\mathrm{ZrO}_{2}$ nanoparticles and (B) $\mathrm{BNFT}$ bone cement containing functionalized BaSO ${ }_{4}$ nanoparticles. Representative compressive stress-strain curves for $(\mathbf{C})$ various bone cements containing $\mathrm{ZrO}_{2}$ particles, and (D) bone cements containing $\mathrm{BaSO}_{4}$ particles. (E) Twenty-four-hour osteoblast adhesion tests showing cell adhesion density as a function of bone cements type. ${ }^{\Psi}$ Compared to bone cements containing micron $\mathrm{BaSO}_{4}$ particles, adhesion was found to be greater on bone cements containing $\mathrm{BaSO}_{4}$ nano-particles functionalized with TMS (P<0.05). ${ }^{€ W R T}$ bone cements containing micron $\mathrm{ZrO}_{2}$ particles, adhesion was found to be greater on bone cements containing unfunctionalized $\mathrm{ZrO}$, nano-particles $(P<0.05)$ and $\mathrm{ZrO}$, nano-particles functionalized with TMS $(P<0.1)$. Copyright @20I0. Dove Medical Press. Reproduced from Gillani R, Ercan B, Qiao A, Webster TJ. Nanofunctionalized zirconia and barium sulfate particles as bone cement additives. Int J Nanomedicine. 2010;5: I-11.79

Abbreviations: $\mathrm{BM}, \mathrm{BaSO}_{4}$ micron particles; $\mathrm{BN}, \mathrm{BaSO}_{4}$ nanoparticles; TMS, 3-(trimethoxysilyl) propyl methacrylate; $\mathrm{BNFT}$, BaSO ${ }_{4}$ nanoparticles functionalized with TMS; $\mathrm{ZM}, \mathrm{ZrO}_{2}$ micron particles; $\mathrm{ZN}, \mathrm{ZrO}_{2}$ nanoparticles; $\mathrm{ZNFT}, \mathrm{ZrO}_{2}$ nanoparticles functionalized with TMS. 
cement containing $\mathrm{ZrO}_{2}$ nanoparticles when compared with cement containing microparticles. In addition to the effect of decreased size, surface modification of a nanosized radiopacifier is also effective in improving both the biological and mechanical properties of bone cement. ${ }^{36}$ For example, PMMA bone cements containing $\mathrm{ZrO}_{2}$ nanoparticles functionalized with 3-(trimethoxysilyl)propylmethacrylate showed greater in vitro osteoblast adhesion and improved mechanical strength when compared with conventional bone cements containing micron-sized particles. Mechanical tests also revealed that the failure modes of bone cement containing functionalized $\mathrm{ZrO}_{2}$ nanoparticles were less brittle and had a clear plastic deformation region. Moreover, bone cements containing functionalized nanoparticles showed greater radiopacity than their nonfunctionalized counterparts.

Since CPC and CSC are biodegradable, radiopaque particles added to these cements can be released into the surrounding tissue as the cement degrades. Radiopacifiers such as $\mathrm{BaSO}_{4}$ and $\mathrm{ZrO}_{2}$ are barely soluble, and release of such particles may result in a biocompatibility hazard. Due to their large surface area-to-volume ratio, a lower concentration of radiopaque nanoparticles can have the same radiopacity as a large amount of micron-sized radiopacifier. This reduced dosage may have less of an adverse biological effect. In addition, biocompatible nanoparticles, such as iron oxide, ${ }^{81}$ alumina, ${ }^{82}$ strontium-modified titanium nanotubes, ${ }^{83}$ and tantalum pentoxide ${ }^{84}$ have shown improved radiopacity when blended with bone cements. Since nanosized radiopacifiers may have greater radiopacity than their micron-sized counterparts, this advantage allows the nanoparticle modified-bone cement to have higher resolution and contrast when compared with the surrounding tissue, which is likely to allow patients to be subjected to lower X-ray doses. ${ }^{39}$

\section{Nanotechnology-enhanced instruments for treatment of OVF Balloon catheter for kyphoplasty}

A balloon catheter comprises a thin catheter tube and a distensible balloon located at the distal end of the catheter. ${ }^{85}$ A balloon catheter is the key instrument used in kyphoplasty to create a cavity in the compressed or fractured vertebral body, thereby recovering the height of the fractured vertebra while creating room for cement reinforcement. However, a common complication of kyphoplasty is leakage of cement from the vertebral body, which may cause pulmonary embolism, nerve damage, paralysis, and even death. ${ }^{86,87}$ Special balloon catheters have been developed for restoring the height of a vertebral body or reducing/avoiding cement leakage. ${ }^{88-90}$ However, most of these balloon catheters are non-degradable and needed to be removed prior to the injection of bone cement.

Recently, degradable nanofibrous poly(D,L-lactideco- $\varepsilon$-caprolactone) balloons (ENPBs) were prepared by electrospinning (Figure 5). ${ }^{91}$ Preliminary studies showed that these nanotechnology-enhanced balloon catheters could separate the cement from the surrounding environment, indicating an ability to eliminate cement leakage and prevent the water-induced collapse of cement often seen with CPC. ENPBs filled with CPC also showed enough strength to restore the height of a fractured vertebral body. Further, ENPBs showed good biodegradability and cytocompatibility, and calcium-based bone cements can release calcium ions throughout the ENPB membrane. These advantages suggest that ENPBs could be effective balloon catheters for CPC cement, enabling simple, convenient, and safe delivery of bone cements in kyphoplasty.

\section{Pedicle screws}

Pedicle screws usually serve as anchoring points for implantation of spinal instrumentation in the treatment of spinal fractures and deformities. The strength of the screw in contact with the surrounding bone diminishes as the bone degrades due to osteoporosis, which would cause screw loosening and subsequent instability in spinal instrumentation or even fixation failure..$^{92}$ Different strategies have been investigated for their ability to improve the fixation efficacy of pedicle screws in osteoporotic bone, including adjustments in thread design and screw shape as well as surface modification of the screws. ${ }^{93}$ In the past few years, nanostructural modification of the surface of titanium pedicle screws has yielded promising results in research and clinical tests. It is now widely accepted that the surface topography of titanium and its alloys affects the attachment, proliferation, and differentiation of osteoblasts. This understanding is important for enhancing the osseointegrative capability of bone screws. Compared with screws made from uncoated Ti6Al4V and conventional HA-coated Ti6Al4V, a nanosized HA coating on Ti6Al4V screws significantly enhanced the fixation efficacy of the screws and led to better stability, bone ingrowth, and osseointegration. ${ }^{94}$ Figure 6 shows images of Ti6A14V and bioabsorbable screws before and after nano-HA coating. The variation in failure loads for coated Ti6Al4V interference screws after extraction are shown in Figure 6E. The nano HA-coated Ti6Al4V interference screws also showed good osteoblastic activity and minimal formation of vascular granulation tissue.

Nano-HA coatings have not been tested in humans, but Olerud et $\mathrm{al}^{95}$ investigated the effects of HA coating on pedicle screws made from wrought stainless steel (SAF 

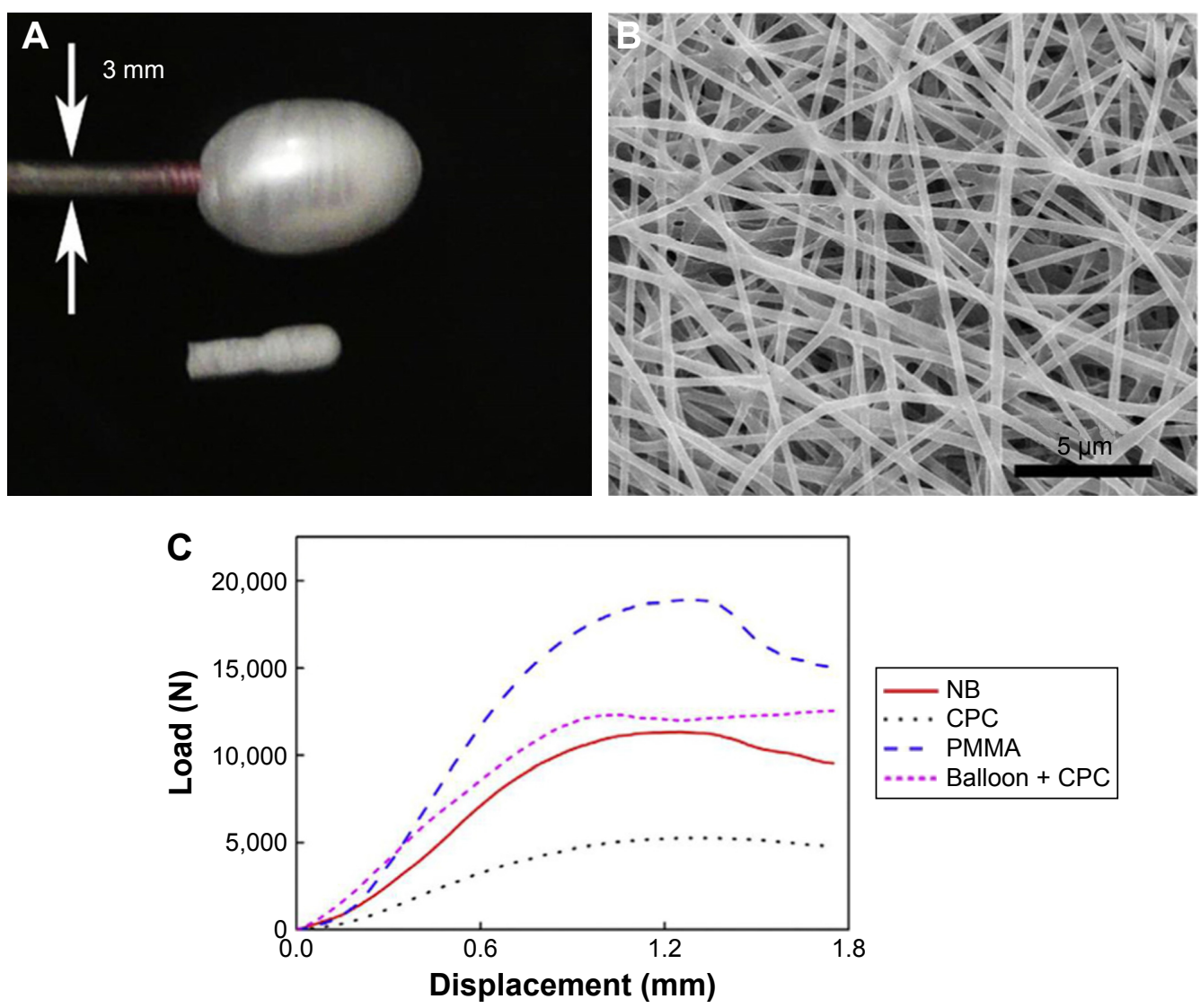

Figure 5 Morphology and mechanical property of electrospun nanofibrous P(DLLA-CL) balloons (ENPBs).

Notes: (A) Photograph of inflated (top) and non-inflated (bottom) ENPBs. Arrows indicate the diameter of balloon catheter. (B) Scanning electron micrograph of electrospun nanofibers in an ENPB. (C) Typical force-displacement curves for natural bones, nature bones injected with CPC, natural bones injected with PMMA, and natural bones with balloon insertion and CPC injection, respectively. Reprinted from Nanomedicine. Vol 9. Sun G, Wei D, Liu X, et al. Novel biodegradable electrospun nanofibrous P(DLLA-CL) balloons for the treatment of vertebral compression fractures. 829-838;20I3, with permission from Elsevier.91

Abbreviations: CPC, calcium phosphate cement; ENPB, electrospun nanofibrous poly(D,L-lactide-co- $\varepsilon$-caprolactone) balloon; NB, nature bone; PMMA, polymethylacrylate.
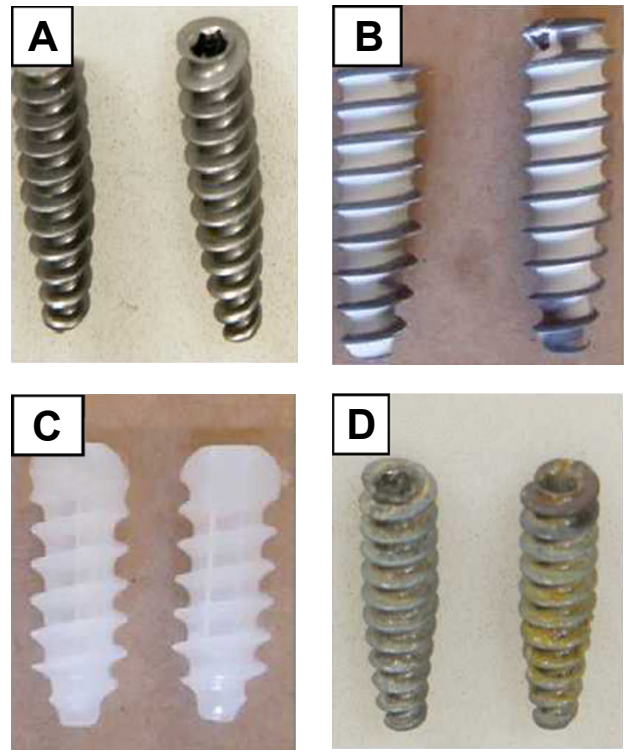

E

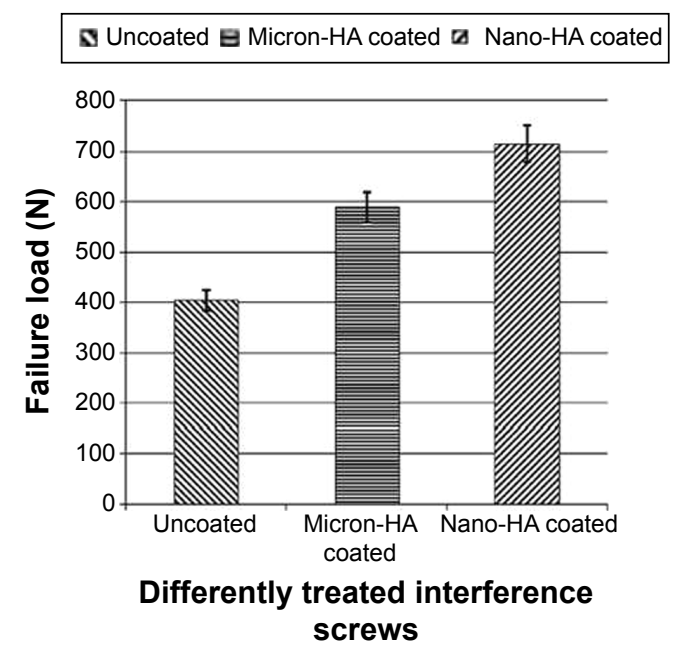

Figure 6 Images and failure loads of metallic interference screws before and after coating with HA.

Notes: Photographs of metallic (Ti6Al4V) interference screws (A) before and (B) after coating with nano-HA, (C) bioabsorbable interference screws, and (D) metallic screws retrieved after implantation. (E) Failure loads of metallic interference screws coated with micro-HA and nano-HA after extraction, compared with uncoated screws. Reproduced from Springer and Eur J Orthop Surg Traumatol.Vol 24, 20I4:8I3-8I9. Influence of micro- and nano-hydroxyapatite coatings on the osteointegration of metallic (Ti6Al4V) and bioabsorbable interference screws: an in vivo study. Aksakal B, Kom M, Tosun HB, Demirel M.With kind permission from Springer Science and Business Media. ${ }^{94}$ Abbreviation: HA, hydroxyapatite. 
2507). In their study, 23 consecutive patients undergoing lumbar fusion were randomly assigned to one of three treatment groups. The first group received uncoated stainless steel screws, the second group received screws partly coated with $\mathrm{HA}$, and the third group received screws fully coated with HA. After 11-16 months, 21 screws had been extracted and the extraction torque was recorded. At removal, the extraction torques exceeded the upper limit of the torque wrench $(600 \mathrm{~N} \cdot \mathrm{cm})$ for many HA-coated screws. The calculated mean extraction torque was $29 \pm 36 \mathrm{~N} \cdot \mathrm{cm}$ for the uncoated group, $447 \pm 114 \mathrm{~N} \cdot \mathrm{cm}$ for the partly coated group, and $574 \pm 52 \mathrm{~N} \cdot \mathrm{cm}$ for the fully-coated group $(P<0.001)$. Radiographs showed more radiolucent zones surrounding the uncoated screws than the HA-coated screws $(P<0.001)$. The results suggested that HA coating of pedicle screws resulted in improved fixation with a reduced risk of loosening of the screws.

Anodization is another promising nanotechnology to improve osseointegrative ability on titanium. ${ }^{96}$ A large number of studies have confirmed that adhesion, proliferation, and differentiation of osteoblasts are enhanced on anodized nanotubular titanium when compared with titanium surfaces containing anodized nanoparticles or without anodization. ${ }^{97}$ These enhancements are arguably attributed to the increased initial adsorption of vitronectin and fibronectin (proteins known to promote cell adhesion) on the anodized nanotubular titanium compared with other titanium surfaces. For example, a cytocompatibility study of anodized nanotubular substrates showed that a $33 \%$ increase in osteoblast adhesion, which was correlated with a $18 \%$ increase in vitronectin adsorption and a $30 \%$ increase in fibronectin adsorption onto anodized titanium when compared with conventional titanium. ${ }^{98}$ Studies also suggest a possibly higher clinical success rate for the anodized titanium implants in comparison with titanium surfaces of similar shape without anodization. In addition, when compared with conventional titanium screws, the anodized titanium screws resulted in enhanced skin growth and decreased infection. ${ }^{99}$ Similarly, Oha et a ${ }^{100}$ reported enhanced osteogenic differentiation of mesenchymal stem cells cultured on anodized nanotubular titanium compared with conventional titanium samples. They also reported that osteoblasts deposited more calcium and synthesized more osteocalcin, which are important for bone formation, on anodized titanium compared with conventional titanium.

Infection of an orthopedic implant is another problem needing to be resolved. Some researchers have demonstrated that certain nanosized titanium topographies may be useful for reducing bacterial adhesion while promoting formation of bone tissue. ${ }^{101-103}$ Puckett et al ${ }^{104}$ showed that the surface features of nanosized titanium are possibly a simple means for reducing bacterial adhesion and subsequent infection on titanium implants like pedicle screws. Specifically, nanorough titanium surfaces showed decreased adhesion of $S$. aureus, S. epidermidis, and Pseudomonas aeruginosa (three types of bacteria commonly associated with orthopedic implant infection), while nanotubular and nanorough titanium created by anodization resulted in increased bacterial attachment. Figure 7 shows the surface features of conventional titanium, anodized nanotubular titanium, fibronectin adsorption, and growth of bacteria cultured on conventional and anodized nanotubular titanium for 1 hour. Figure $7 \mathrm{C}$ shows that titanium with appropriate nanotopography may be useful for reducing bacterial adhesion while promoting formation of new bone, and so should be further studied for improving the efficacy of titanium-based instruments like pedicle screws.

\section{PEEK-based spinal implants}

Polyether-ether-ketone (PEEK) has recently been attracting attention as a high-strength polymer with favorable imaging compatibility and stiffness that closely matches bone, rendering it suitable for orthopedic, trauma, and spinal implant applications. ${ }^{105,106}$ For spinal implants, PEEK has many advantages, including excellent mechanical properties, chemical inertness, ease of processing, biocompatibility, low toxicity, and radiolucency. PEEK and PEEK-based composites are commonly used for fabricating spinal fusion cages. ${ }^{107}$ However, PEEK faces the problem of insufficient osseointegrative capability and the common solution of adding HA to PEEK suffers from dramatically decreased mechanical strength. To solve this problem, nanophase HA has been combined with PEEK and showed better mechanical properties due to the strong adhesion of HA fillers to the PEEK matrix. ${ }^{108}$ Figure $8 \mathrm{~A}$ and $\mathrm{B}$ show TEM images of PEEK-HA nanocomposites with $5.0 \mathrm{vol} \%$ and $15.0 \mathrm{vol} \%$ HA content. The nanocomposite showed enhanced mechanical properties, with tensile strength increased from $92 \mathrm{MPA}$ to $98 \mathrm{MPa}$ and hardness increased from $23 \mathrm{HV}$ to $27 \mathrm{HV}$ when the HA content increased from 0 vol $\%$ to 5 vol\% (Figure $8 \mathrm{C}$ ). ${ }^{109}$ The study also revealed that well-dispersed HA nanoparticles bonded strongly to PEEK and no debonding was observed, suggesting that using nanoparticles is a possible solution to the debonding problem encountered with current PEEK-HA composites. However, the tensile strength decreased from $98 \mathrm{MPa}$ to $24 \mathrm{MPa}$ as the HA content increased from $5 \mathrm{vol} \%$ to $10 \mathrm{vol} \%$ due to widespread agglomeration of HA nanoparticles.

In a further attempt to avoid agglomeration of HA nanoparticles, a novel PEEK/HA nanocomposite was developed by in situ synthesis. ${ }^{110}$ In this process, HA particles were first 
A

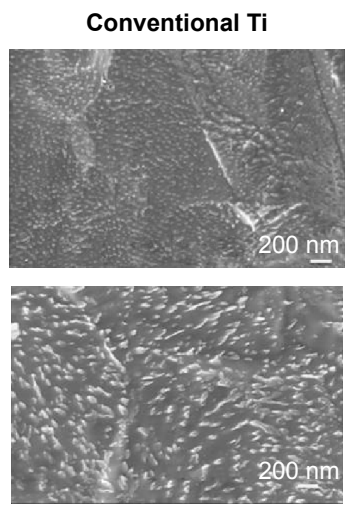

Nanotextured Ti

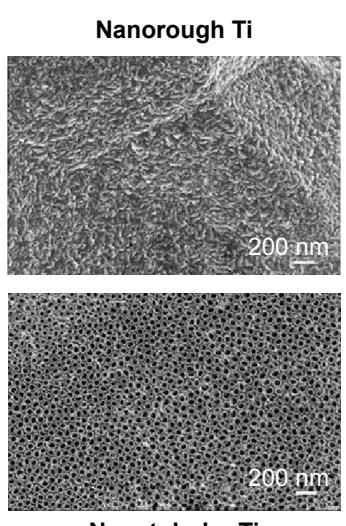

Nanotubular Ti

B

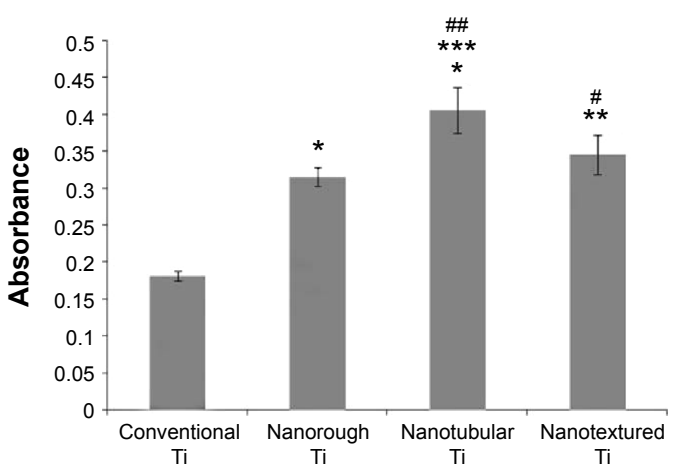

C

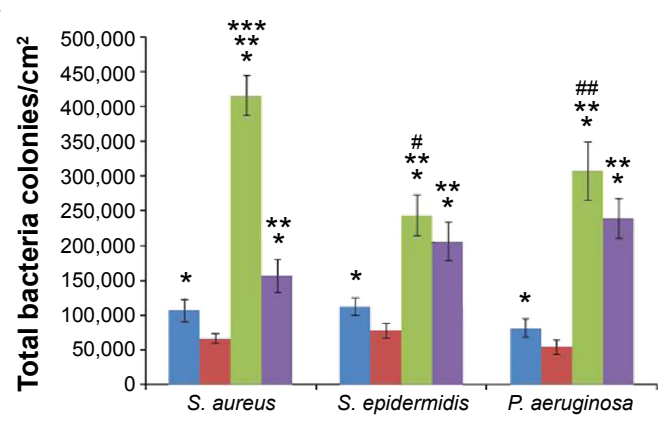

D

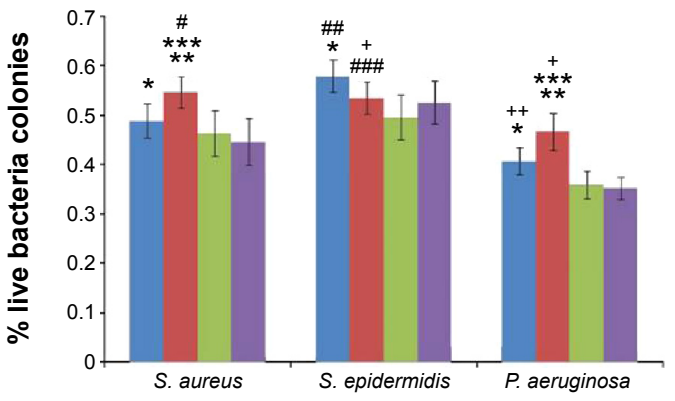

E Conventional $\mathrm{Ti}$ Nanorough $\mathrm{Ti} \equiv$ Nanotubular $\mathrm{Ti} \quad$ Nanotextured $\mathrm{Ti}$

Figure 7 Morphology and antibacterial capacity of conventional Ti, nanorough Ti, nanotubular Ti, and nanotextured Ti.

Notes: (A) Scanning electron micrographs of (clockwise) conventional Ti as purchased, nanorough Ti fabricated by electron beam evaporation, nanotextured Ti fabricated by anodization for I minute in $0.5 \%$ hydrofluoric acid at $20 \mathrm{~V}$, and nanotubular Ti fabricated by anodization for 10 minutes in I.5\% hydrofluoric acid at $20 \mathrm{~V}$. Scale bar $200 \mathrm{~nm}$. (B) Increased fibronectin adsorption on nanorough, nanotubular, and nanotextured Ti surfaces compared with conventional Ti surface. (C) Decreased Staphylococcus aureus, Staphylococcus epidermidis, and Pseudomonas aeruginosa colonies on nanorough and conventional Ti surfaces compared with nanotubular and nanotextured Ti surfaces after I hour. (D) The highest percentage of live bacteria colonies for S. aureus, S. epidermidis, and P. aeruginosa attached to the nanorough Ti surfaces after I hour compared with the conventional, nanotextured, and nanotubular Ti surfaces. $* P<0$.I compared to nanotextured Ti; $* * P<0.01$ compared to nanotextured Ti; $* * * P<0.05$ compared

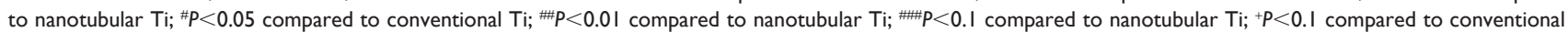
$\mathrm{Ti} ;{ }^{+} P<0$.I compared to nanotubular Ti for respective bacteria lines. Reprinted from Biomaterials. Vol 3I. Puckett S, Taylor E, Raimondo T, Webster TJ. The relationship between the nanostructure of titanium surfaces and bacterial attachment. 706-713;2010, with permission from Elsevier. ${ }^{104}$

Abbreviation: $\mathrm{Ti}$, titanium.

mixed into PEEK oligomers with short chains to achieve low viscosity, good wetting, and contact between HA nanoparticles and PEEK molecules. The PEEK oligomers then started to polymerize and wrap HA nanoparticles in the PEEK matrix. The tensile strength of the HA/PEEK composite reached as high as $108 \mathrm{MPa}$ at an HA content of $6.1 \%$. The composites with an HA content below $17.4 \%$ exhibited a plastic fracture mode, while a brittle fracture mode was observed in the composites with HA content above $17.4 \%$.

To improve the mechanical and biological properties of PEEK, nano- $\mathrm{TiO}_{2}$ reinforced PEEK composites $\left(\mathrm{n}-\mathrm{TiO}_{2} /\right.$ PEEK) have been studied. ${ }^{111}$ In vitro tests showed that $\mathrm{n}-\mathrm{TiO}_{2}$ promoted cell attachment and improved osteoblast spreading. In vivo tests showed that $\mathrm{n}-\mathrm{TiO}_{2}$ improved bone regeneration around the implants compared with pure PEEK, as assessed by micro-computed tomography and histological analysis. $\mathrm{Li}$ et al ${ }^{112}$ fabricated HA/PEEK nanocomposites containing 15.1, 21.6, 29.2, and 38.2 vol\% nanosized HA and reported that the tensile strength and fracture strain of the nanocomposites filled with $21.6 \mathrm{vol} \%$ and $29.2 \mathrm{vol} \%$ nanosized HA closely matched those of human cortical bone. In vitro tests of immersion, cell adhesion, and proliferation in simulated body fluid also suggested that the $29.2 \mathrm{vol} \%$ nano HA/PEEK nanocomposite had better biocompatibility than the other specimens. Therefore, development of PEEK composites containing nanosized bioactive materials may be an effective way of obtaining both mechanical and biological benefits for PEEK-based spinal implants.

\section{Safety concerns with nanotechnology}

Nanotechnology offers vast potential for massive improvement in the field of orthopedic repair and regeneration, 

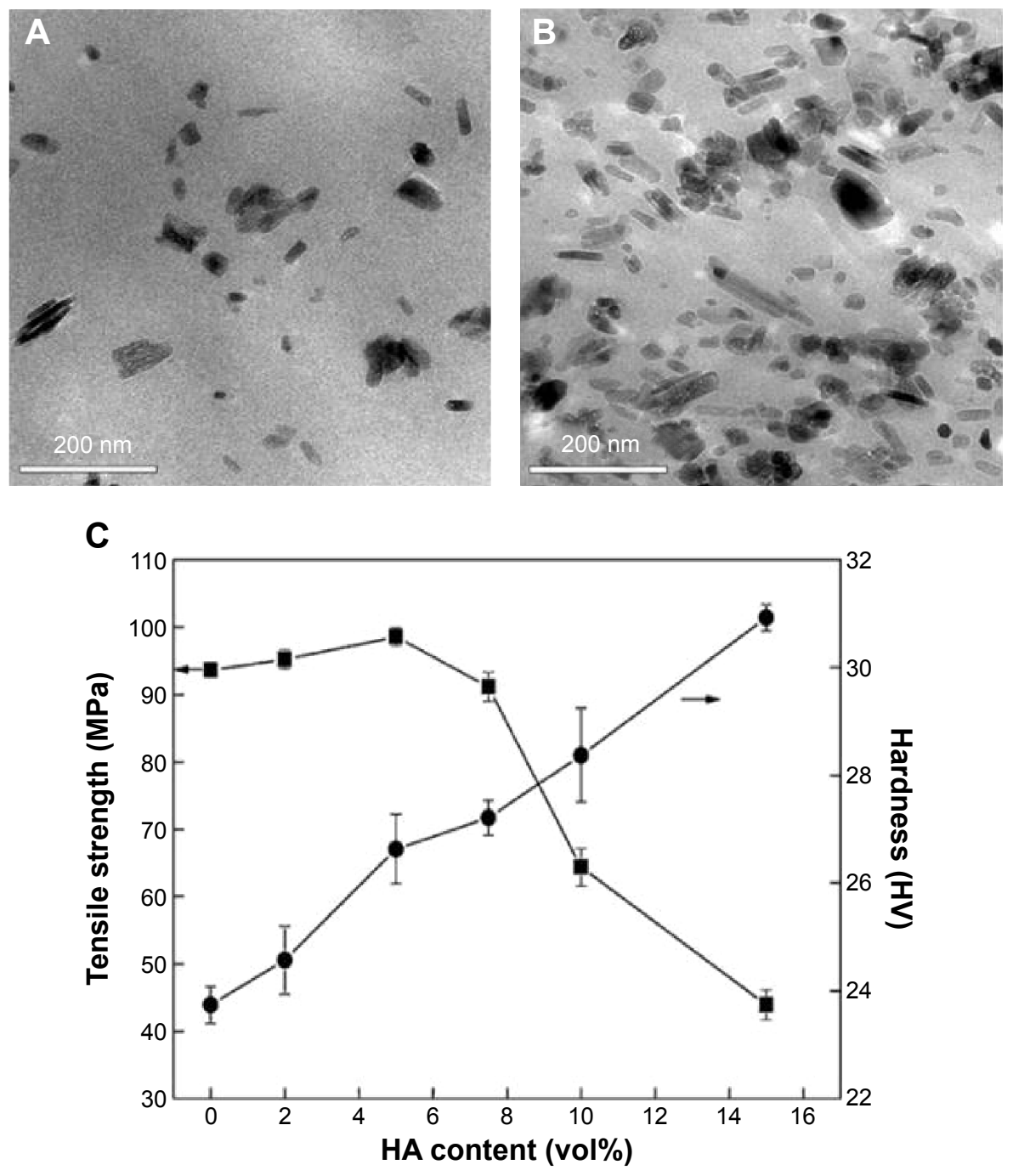

Figure 8 Transmission electron micrographs of PEEK-HA nanocomposites with (A) 5.0 vol\% and (B) 15.0 vol\% HA content. (C) Ultimate tensile strength and microhardness of PEEK-HA nanocomposites as a function of HA content.

Note: The arrow in C means the micro-hardness of the nanocomposites. Reprinted from Mater Sci Eng A. Vol 528 (I0-I I). Wang L, Weng LQ, Song SH, Zhang ZG, Tian SL, Ma R. Characterization of polyetheretherketone-hydroxyapatite nanocomposite materials. 3689-3696; 20II, with permission from Elsevier. ${ }^{108}$

Abbreviations: HA, hydroxyapatite; PEEK, polyether-ether-ketone.

particularly with regard to improving the interaction between host bone and the implant. ${ }^{113}$ Injectable nanomaterial and nanotechnology-enhanced instruments have demonstrated their superior properties in terms of bioactivity, radiopacity, mechanical strength, antibacterial effect, and osseointegration when compared with traditional materials and unmodified instruments. ${ }^{114}$ However, the safety concern is still an important issue in implementing nanotechnology for the treatment of OVF and other orthopedic problems. For example, nanophase silver is of significant interest for preventing infections. However, silver nanoparticles themselves also have severe toxicity due to their size and shape and the silver ions released. ${ }^{115}$ As a result, a lot of nanosilver-embedded composites developed to date have come with a risk of uncontrollable toxicity during degradation of the implanted composite in humans. The aforementioned $\mathrm{BaSO}_{4}$ nanoparticles that were added to bone cements ${ }^{116}$ also face the health risk of released barium ions, and the long-term influence of $\mathrm{BaSO}_{4}$ nanoparticles on human health is still unclear. Obviously, further studies on the extensive toxicity and safety risks of nanotechnology are necessary before nanotechnology can be translated into clinical treatments.

\section{Summary and future directions}

Emergence of nanotechnology has provided new strategies for improving the properties of biomedical materials for orthopedic applications. In this article we have summarized the recent progress and perspectives in nanotechnology for the surgical treatment of OVF. For developing better bone cements and 
surgical instruments for minimally invasive vertebroplasty and kyphoplasty, incorporating nanomaterials (eg, nanoparticles, nanofibers, nanocrystals) has been demonstrated to be an effective means of improving the biological properties, radiopacity, mechanical properties, and safety of bone cements, from PMMA to CPC. The positive and effective role of nanomaterials is probably a result of the appropriate surface roughness, nanotopography, hydrophobicity, and surface area generated by adding nanomaterials, which is favorable for cellular activity, protein absorption, enhanced radiopacity, and strengthening the interaction between nanoscale additives and bone cement components. Further research on these mechanisms may potentially lead to new bone cements or surgical tools with improved efficacy. Despite the fact that nanophase composites have shown great potential for improving bone cements or surgical instruments used for treating OVF, problems and unknown risks associated with these materials remain.

Future directions in this area are likely to encompass the following aspects. Firstly, extensive investigations on the agglomeration problem, toxicology, and safety concerns regarding nanoscale additives for bone cements or implantable materials will continue. In addition, optimized parameters for fabrication and modification of such nanocomposites will be further studied. Secondly, a number of new nanomaterials such as injectable hydrogels with advanced properties, including sensing, detecting, and environment-responsive capabilities are expected to play a more important role in the treatment of OVF. These new materials will be administered to defective sites in less invasive ways and allow more functionalities for drug delivery, cell therapy, and theranostic treatment of spinal fractures. Compared with the bone cements and metallic implants mentioned above, these materials are smart and responsive to temperature, $\mathrm{pH}$, light, ionic, or biological change. Although many of these new smart biomaterials show promise, it is still challenging to use these materials for the treatment of OVF due to insufficient mechanical strength. Therefore, the third research direction will be to enhance the mechanical properties of bone cements for wider application in load-bearing bones including the spine. This review has shown some possible approaches to reinforce new smart materials like hydrogel by incorporating nanomaterials into its network, but further studies in this direction are still needed. Lastly, studies aiming at improving biocompatibility or osseointegration properties of spinal implants and decreasing the risk of infection associated with these implants are also of great interest. It is known that surface properties of metallic implants can directly affect bone and bacterial behaviors in both the short and long term. Therefore, surface modification through nanotechnology is expected to play an important role in design and fabrication of better spinal implants.

\section{Acknowledgments}

The authors would like to thank the Jiangsu Provincial Special Program of Medical Science (BL2012004), the project funded by the Priority Academic Program Development of Jiangsu High Education Institutions, National Basic Research Program of China (973 Program, 2014CB748600), the Jiangsu R\&D Innovation Program (BY2014059-07), the National Natural Science Foundation of China (51472279), the Jiangsu Six Peak of Talents Program (2013-WSW-056), the Chinese Ministry of Education Star-up Fund for Oversea Scholars, and the Open Fund of State Key Laboratory of Nonlinear Mechanics for supporting this work.

\section{Disclosure}

The authors report no conflicts of interest in relation to this work.

\section{References}

1. Cummings SR, Black DM, Rubin SM. Lifetime risks of hip, Colles, or vertebral fracture and coronary heart disease among white postmenopausal women. Arch Intern Med. 1989;149:2445-2448.

2. World Health Organization. Assessment of fracture risk and its application to screening for postmenopausal osteoporosis. Report of a WHO Study Group. World Health Organ Tech Rep Ser. 1994; 843:1-129.

3. Messina C, Bandirali M, Sconfienza LM. Prevalence and type of errors in dual-energy x-ray absorptiometry. Eur Radiol. 2015;25:1504-1511.

4. Pisani P, Renna MD, Conversano F. Screening and early diagnosis of osteoporosis through X-ray and ultrasound based techniques. World $J$ Radiol. 2013;5:398-410.

5. Conversano F, Franchini R, Greco A. A Novel ultrasound methodology for estimating spine mineral density. Ultrasound Med Biol. 2015;41: 281-300.

6. Sunyecz JA. The use of calcium and vitamin D in the management of osteoporosis. Ther Clin Risk Manag. 2008;4:827-836.

7. Hernlund E, Svedbom A, Ivergård M, et al. Osteoporosis in the European Union: medical management, epidemiology and economic burden. Arch Osteoporos. 2013;8:136.

8. Boughton B, Odle T. Osteoporosis. In: Longe JL. The Gale Encyclopedia of Medicine. 3rd ed. Farmington Hills, MI, USA: Thompson Gale; 2006.

9. International Osteoporosis Foundation. Invest in your bones. Osteoporosis in the workplace. Available from: http:/www.bbcbonehealth.org/ documents/workplacereportEN.pdf. Accessed June 6, 2015.

10. Liao RX, Yu M, Jiang Y, Xia WB. Management of osteoporosis with calcitriol in elderly Chinese patients: a systematic review. Clin Interv Aging. 2014;9:515-526.

11. Kenneth GS, Piet G. Progress in osteoporosis and fracture prevention: focus on postmenopausal women. Arthritis Res Ther. 2009;11:251.

12. Kenneth ES, Jonathan RP, Elizabeth AW. Falls, fractures, and osteoporosis after stroke - time to think about protection? Stroke. 2002;33: 1432-1436. 
13. Eastell R, Cedel SL, Wahner HW, et al. Classification of vertebral fractures. J Bone Miner Res. 1991;6:207-215.

14. He ZW, Zhai QP, Hu ML, et al. Bone cements for percutaneous vertebroplasty and balloon kyphoplasty: current status and future developments. J Orthop Translation. 2015;3:1-11.

15. Cosman F, Beur SJ, LeBoff MS, et al. Clinician's guide to prevention and treatment of osteoporosis. Osteoporos Int. 2014;25:2359-2381.

16. Ulmar B, Brunner A, Gühring M, Schmälzle T, Weise K, Badke A. Inter- and intraobserver reliability of the vertebral, local and segmental kyphosis in 120 traumatic lumbar and thoracic burst fractures: evaluation in lateral X-rays and sagittal computed tomographies. Eur Spine J. 2010;19:558-566.

17. Freedman BA, Potter BK, Nesti LJ, Giuliani JR, Hampton C, Kuklo TR. Osteoporosis and vertebral compression fractures - continued missed opportunities. Spine J. 2008;8:756-762.

18. Prather H, Watson JO, Gilula LA. Nonoperative management of osteoporotic vertebral compression fractures. Injury. 2007;38:S40-S48.

19. Nakashima H, Yukawa $Y$, Ito K, Machino M, Ishiguro N, Kato F Combined posterior-anterior surgery for osteoporotic delayed vertebral fracture with neurologic deficit. Nagoya J Med Sci. 2014;76:307-314.

20. Koes BW, Tulder MW, Peul WC. Diagnosis and treatment of sciatica. BMJ. 2007;23:1313-1317.

21. Marcucci G, Brandi ML. Kyphoplasty and vertebroplasty in the management of osteoporosis with subsequent vertebral compression fractures Clin Cases Miner Bone Metab. 2010;7:51-60.

22. Galibert P, Deramond H, Rosat P, Le Gars D. Note préliminaire sur le traitement des angiomes vertébraux par vertébroplastie acrylique percutanée [Preliminary note on the treatment of vertebral angioma by percutaneous acrylic vertebroplasty]. Neurochirurgie. 1987;33:166-168. French.

23. Cloft HJ, Jensen ME. Kyphoplasty: an assessment of a new technology. Am J Neuroradiol. 2007;28:200-203.

24. Spivak JM, Johnson MG. Percutaneous treatment of vertebral body pathology. J Am Acad Orthop Surg. 2005;13:16-17.

25. Hadjipavlou AG, Tzermiadianos MN, Katonis PG, Szpalski M. Percutaneous vertebroplasty and balloon kyphoplasty for the treatment of osteoporotic vertebral compression fractures and osteolytic tumours. J Bone Joint Surg Br. 2005;87:1595-1604.

26. Mathis JM, Ortiz AO, Zoarski GH. Vertebroplasty versus kyphoplasty: a comparison and contrast. AJNR Am J Neuroradiol. 2004; 25:840-845.

27. Bouza C, López-Cuadrado T, Cediel P, Saz-Parkinson Z, Amate JM Balloon kyphoplasty in malignant spinal fractures: a systematic review and meta-analysis. BMC Palliat Care. 2009;8:12-21.

28. Van Meirhaeghe J, Bastian L, Boonen S, Ranstam J, Tillman JB, Wardlaw D. A randomized trial of balloon kyphoplasty and nonsurgical management for treating acute vertebral compression fractures: vertebral body kyphosis correction and surgical parameters. Spine (Phila Pa 1976). 2013;38:971-983.

29. Rotter R, Martin H, Fuerderer S, et al. Vertebral body stenting: a new method for vertebral augmentation versus kyphoplasty. Eur Spine J. 2010 19:916-923.

30. David B, Laurie AK. Disadvantages of infection surveillance by medical record chart review. Am J Infect Control. 1981;9:15-17.

31. Engel E, Michiardi A, Navarro M, Lacroix D, Planell JA. Nanotechnology in regenerative medicine: the materials side. Trends Biotechnol. 2008;26:39-47.

32. Liu H, Webster TJ. Nanomedicine for implants: a review of studies and necessary experimental tools. Biomaterials. 2007;28:354-369.

33. Zhang LJ, Webster TJ. Nanotechnology and nanomaterials: promises for improved tissue regeneration. Nano Today. 2009;4:66-80.

34. Hassim A, Rachmawati H. Preparation and characterization of calcium carbonate nanoparticles. The third nanoscience and nanotechnology symposium 2010. AIP Publishing. 2010;1284(1):195-198.

35. Larsson S. Cement augmentation in fracture treatment. Scand J Surg. 2006;95:111-118.

36. Arora M, Chan EK, Gupta S, Diwan AD. Polymethylmethacrylate bone cements and additives: a review of the literature. World J Orthop. 2013; $4: 67-74$.
37. Barinov SM, Komlev VS. Calcium phosphate bone cements. Inorg Mater. 2011;47:1470-1485.

38. Nelson CL, McLaren SG, Skinner RA, Smeltzer MS, Thomas JR, Olsen KM. The treatment of experimental osteomyelitis by surgical debridement and the implantation of calcium sulfate tobramycin pellets. J Orthop Res. 2002;20:643-647.

39. No YJ, Roohani-Esfahani SI, Zreiqat H. Nanomaterials: the next step in injectable bone cements. Nanomedicine (Lond). 2014;9:1745-1764.

40. Rodriguez LC, Chari J, Aghyarian S, Gindri IM, Kosmopoulos V, Rodrigues DC. Preparation and characterization of injectable brushite filled-poly (methyl methacrylate) bone cement. Materials. 2014;7:6779-6795.

41. Harper EJ. Bioactive bone cements. Proc Inst Mech Eng H. 1998; 212:113-120.

42. Glimcher MJ. PMMA. Instr Course Lect. 1987;36:49.

43. Ricker A, Liu-Snyder P, Webster TJ. The influence of nano $\mathrm{MgO}$ and $\mathrm{BaSO}_{4}$ particle size additives on properties of PMMA bone cement. Int J Nanomedicine. 2008;3:125-132.

44. Boger A, Bohner M, Heini P. Properties of an injectable low modulus PMMA bone cement for osteoporotic bone. J Biomed Mater Res B Appl Biomater. 2008;86:474-482.

45. Alt V, Bechert T, Steinrücke P. An in vitro assessment of the antibacterial properties and cytotoxicity of nanoparticulate silver bone cement. Biomaterials. 2004;25:4383-4391.

46. Brown WE, Chow LC. A new calcium phosphate setting cement. J Dent Res. 1983;62:672-679.

47. Chow LC, Eanes ED. Calcium phosphate cement. Monogr Oral Sci. 2001;18:148-163.

48. Nakano M, Hirano N, Matsuura K, et al. Percutaneous transpedicular vertebroplasty with calcium phosphate cement in the treatment of osteoporotic vertebral compression and burst fractures. J Neurosurg. 2002;97(3 Suppl):287-293.

49. Oner FC, Verlaan JJ, Verbout AJ, Dhert WJ. Cement augmentation techniques in traumatic thoracolumbar spine fracture. Spine (Phila Pa 1976). 2006;31(11 Suppl):S89-S95.

50. Verlaan JJ, Dhert WJ, Verbout AJ, Oner FC. Balloon vertebroplasty in combination with pedicle screw instrumentation: a novel technique to treat thoracic and lumbar burst fractures. Spine (Phila Pa 1976). 2005;30:E73-E79.

51. Low KL, Tan SH, Zein SHS, McPhail DS, Boccaccini AR. Optimization of the mechanical properties of calcium phosphate/multi-walled carbon nanotubes/bovine serum albumin composites using response surface methodology. Mater Des. 2011;32:3312-3319.

52. Perez RA, Patel KD, Kim HW. Novel magnetic nanocomposite injectables: calcium phosphate cements impregnated with ultrafine magnetic nanoparticles for bone regeneration. RSC Adv. 2015;5:13411-13419.

53. El-Fiqi A, Kim J-H, Perez RA, Kim H-W. Novel bioactive nanocomposite cement formulations with potential properties: incorporation of the nanoparticle form of mesoporous bioactive glass into calcium phosphate cements. J Mater Chem B. 2015;3:1321-1334.

54. Ginebra MP, Espanol M, Montufar EB, Perez RA, Mestres G. New processing approaches in calcium phosphate cements and their applications in regenerative medicine. Acta Biomater. 2010;6:2863-2873.

55. Canal C, Ginebra MP. Fibre-reinforced calcium phosphate cements: a review. J Mech Behav Biomed Mater. 2011;4:1658-1671.

56. Wang X, Ye J, Wang Y, Chen L. Reinforcement of calcium phosphate cement by bio-mineralized carbon nanotube. J Am Ceram Soc. 2007;90: 962-964.

57. Chew KK, Low KL, Sharif Zein SH, et al. Reinforcement of calcium phosphate cement with multi-walled carbon nanotubes and bovine serum albumin for injectable bone substitute applications. J Mech Behav Biomed Mater. 2011;4:331-339.

58. Peltier LF. The use of plaster of Paris to fill defects in bone. Clin Orthop Res. 1961;21:1-29.

59. Zhou W, Xue YD, Ji XB, Yin GY, Zhang N, Ren YX. A novel injectable and degradable calcium phosphate/calcium sulfate bone cement. Afr J Biotechnol. 2011;10:19449-19457. 
60. Raki LL, Beaudoin JL, Alizadeh RL, Makar J, Sato TJ. Cement and concrete nanoscience and nanotechnology. Materials. 2010;3:918-942.

61. Hesaraki S, Moztarzadeh F, Nemati R, Nezafati N. Preparation and characterization of calcium sulfate-biomimetic apatite nanocomposites for controlled release of antibiotics. J Biomed Mater Res B Appl Biomater. 2009;91:651-661.

62. Liu X, Wang XM, Chen Z, et al. Injectable bone cement based on mineralized collagen. J Biomed Mater Res B Appl Biomater. 2010;94: 72-79.

63. Li H, Xiao, HG Yuan J, Ou JP. Microstructure of cement mortar with nanoparticles. Compos Part B Eng. 2004;35:185-189.

64. Peng Q, Sun X, Gong T, et al. Injectable and biodegradable thermosensitive hydrogels loaded with PHBHHx nanoparticles for the sustained and controlled release of insulin. Acta Biomater. 2013;9:5063-5069.

65. Abdel-Bar HM, Abdel-Reheem AY, Osman R. Optimized formulation of vancomycin loaded thermoreversible hydrogel for treatment of orthopedic infections. J Pharm Sci. 2014;5:2936-2946.

66. Campbell SB, Patenaude M, Hoare T. Injectable superparamagnets: highly elastic and degradable poly( $\mathrm{N}$-isopropylacrylamide)-superparamagnetic iron oxide nanoparticle (SPION) composite hydrogels. Biomacromolecules. 2013;14:644-653.

67. Cao L, Werkmeuster JA, Wang J, Glattauer V, McLean KM, Liu C. Bone regeneration using photocrosslinked hydrogel incorporating rhBMP-2 loaded 2-N, 6-O-sulfated chitosan nanoparticles. Biomaterials. 2014;35:2730-2742.

68. Kim HH, Park JB, Kang MJ, Park YH. Surface-modified silk hydrogel containing hydroxyapatite nanoparticle with hyaluronic acid-dopamine conjugate. Int J Biol Macromol. 2014;70:516-522.

69. Reddy NN, Varaprasad K, Ravindra S, et al. Evaluation of blood compatibility and drug release studies of gelatin based magnetic hydrogel nanocomposites. Colloids Surf A Physicochem Eng Asp. 2011; 385(1):20-27.

70. Heo DN, Ko WK, Bae MS. Enhanced bone regeneration with a gold nanoparticle-hydrogel complex. J Mater Chem B. 2014;2:1584-1593.

71. Kolambkar YM, Dupont KM, Boerckel JD. An alginate-based hybrid system for growth factor delivery in the functional repair of large bone defects. Biomaterials. 2011;32:65-74.

72. Luhmann T, Germershaus O, Groll J. Bone targeting for the treatment of osteoporosis. J Control Release. 2012;161:198-213.

73. Valente JFA, Gaspar VM, Antunes BP, Countinho P, Correia IJ. Microencapsulated chitosan-dextran sulfate nanoparticles for controlled delivery of bioactive molecules and cells in bone regeneration. Polymer. 2013; 54:5-15.

74. Ignjatović NL, Ninkov P, Sabetrasekh R, Uskoković DP. A novel nano drug delivery system based on tigecycline-loaded calcium phosphate coated with poly-DL-lactide-co-glycolide. J Mater Sci Mater Med. 2010;21:231-239.

75. Nguyen MK, Jeon O, Krebs MD, Schapira D, Alsberg E. Sustained localized presentation of RNA interfering molecules from in situ forming hydrogels to guide stem cell osteogenic differentiation. Biomaterials. 2014;35:6278-6286.

76. Peng KT, Chen CF, Chu IM. Treatment of osteomyelitis with teicoplaninencapsulated biodegradable thermosensitive hydrogel nanoparticles. Biomaterials. 2010;31:5227-5236.

77. Hamdan SA, Ruggero B, Sanne KB, et al. Synergistic effects of bisphosphonate and calcium phosphate nanoparticles on periimplant bone responses in osteoporotic rats. Biomaterials. 2014;35: 5482-5490.

78. Alghamdi HS, Bosco R, Both SK. Synergistic effects of bisphosphonate and calcium phosphate nanoparticles on peri-implant bone responses in osteoporotic rats. Biomaterials. 2014;35:5482-5490.

79. Gillani R, Ercan B, Qiao A, Webster TJ. Nanofunctionalized zirconia and barium sulfate particles as bone cement additives. Int J Nanomedicine. 2010;5:1-11

80. Gomoll AH, Fitz W, Scott RD, Thornhill TS, Bellare A. Nanoparticulate fillers improve the mechanical strength of bone cement. Acta Orthop. 2008;79:421-427.
81. Ajeesh M, Francis BF, Annie J, Harikrishna Varma PR. Nano iron oxide-hydroxyapatite composite ceramics with enhanced radiopacity. J Mater Sci Mater Med. 2010;21:1427-1434.

82. Abboud M, Casaubieilh L, Morvan F, Fontanille M, Duguet E. PMMAbased composite materials with reactive ceramic fillers: IV. Radiopacifying particles embedded in PMMA beads for acrylic bone cements. J Biomed Mater Res. 2000;53:728-736.

83. Khaled SM, Charpentier PA, Rizkalla AS. Synthesis and characterization of poly (methyl methacrylate)-based experimental bone cements reinforced with $\mathrm{TiO}_{2}-\mathrm{SrO}$ nanotubes. Acta Biomater. 2010;6:3178-3186.

84. Hoekstra JW, van den Beucken JJ, Leeuwenburgh SC, Meijer GJ, Jansen JA. Tantalumpentoxide as a radiopacifier in injectable calcium phosphate cements for bone substitution. Tissue Eng C. 2011;17:907-913.

85. Wardlaw D, Cummings SR, Meirhaeghe JV, Bastian L, Rabstam J, Eastell R. Efficacy and safety of balloon kyphoplasty compared with non-surgical care for vertebral compression fracture (FREE): a randomised controlled trial. Lancet. 2009;373:1016-1024.

86. Padovani B, Kasriel O, Brunner P, Peretti-Viton P. Pulmonary embolism caused by acrylic cement: a rare complication of percutaneous vertebroplasty. Am J Neuroradiol. 1999;20:375-377.

87. Mathis JM. Percutaneous vertebroplasty: complication avoidance and technique optimization. Am J Neuroradiol. 2003;24:1697-1706.

88. Antonio K, Ludwig O, Jens F, et al. Height restoration of osteoporotic vertebral compression fractures using different intravertebral reduction devices: a cadaveric study. Spine J. 2015;15:1092-1098.

89. Zheng Z, Luk KD, Kuang G, et al. Vertebral augmentation with a novel vessel-X bone void filling container system and bioactive bone cement. Spine. 2007;32:2076-2082.

90. Heini PF, Orler R. Vertebroplasty in severe osteoporosis. Technique and experience with multi-segment injection. Orthopade. 2004; 33(1):22-30

91. Sun G, Wei D, Liu X, et al. Novel biodegradable electrospun nanofibrous P(DLLA-CL) balloons for the treatment of vertebral compression fractures. Nanomedicine. 2013;9:829-838.

92. Gautschi OP, Schatlo B, Schaller KS, Tessitore E. Clinically relevant complications related to pedicle screw placement in thoracolumbar surgery and their management: a literature review of 35,630 pedicle screws. Neurosurg Focus. 2011;31:E8.

93. Becker S, Chavanne A, Spitaler R. Assessment of different screw augmentation techniques and screw designs in osteoporotic spines. Eur Spine J. 2008;17:1462-1469.

94. Aksakal B, Kom M, Tosun HB, Demirel M. Influence of micro- and nano-hydroxyapatite coatings on the osteointegration of metallic (Ti6A14V) and bioabsorbable interference screws: an in vivo study. Eur J Orthop Surg Traumatol. 2014;24:813-819.

95. Olerud C, Petrén-Mallmin M, Larsson S. Hydroxyapatite coating improves fixation of pedicle screws: a clinical study. J Bone Joint Surg Br. 2002;84:387-391.

96. Kim HS, Yang Y, Koh JT, et al. Fabrication and characterization of functionally graded nano-micro porous titanium surface by anodizing. J Biomed Mater Res B. 2009;88:427-435.

97. Rodriguez R, Kim K, Ong JL. In vitro osteoblast response to anodized titanium and anodized titanium followed by hydrothermal treatment. J Biomed Mater Res A. 2002;65A:352-358.

98. Yao C, Perla V, McKenzie J, Slamovich EB, Webster TJ. Anodized $\mathrm{Ti}$ and Ti6Al4V possessing nanometer surface features enhances osteoblast adhesion. J Biomed Nano. 2005;1:68-73.

99. Ercana B, Webster TJ. The effect of biphasic electrical stimulation on osteoblast function at anodized nanotubular titanium surfaces. Biomaterials. 2010;31(13):3684-3693.

100. Oha S, Brammera KS, Lib YS, et al. Stem cell fate dictated solely by altered nanotube dimension. Proc Natl Acad Sci U S A. 2009; 106:2130-2135.

101. Webster TJ, Ejiofor JU. Increased osteoblast adhesion on nanophase metals: Ti, Ti6Al4V, and CoCrMo. Biomaterials. 2004;25: 4731-4739. 
102. Webster TJ, Siegel RW, Bizios R. Osteoblast adhesion on nanophase ceramics. Biomaterials. 1999;20:1221-1227.

103. Webster TJ, Ergun C, Doremus RH, Siegel RW, Bizios R. Enhanced functions of osteoblasts on nanophase ceramics. Biomaterials. 2000;21: 1803-1810.

104. Puckett S, Taylor E, Raimondo T, Webster TJ. The relationship between the nanostructure of titanium surfaces and bacterial attachment. Biomaterials. 2010;31:706-713.

105. Kurtz SM, Devine JN. PEEK biomaterials in trauma, orthopedic, and spinal implants. Biomaterials. 2007;28:4845-4869.

106. Toth JM, Wang M, Estes BT, Scifert JL, Seim HB III, Turner AS. Polyetheretherketone as a biomaterial for spinal applications. Biomaterials. 2006;27:324-334.

107. Cho DY, Liau WR, Lee WY, Liu JT, Chiu CL, Sheu PC. Preliminary experience using a polyetheretherketone (PEEK) cage in the treatment of cervical disc disease. Neurosurgery. 2002;51:1343-1349.

108. Wang L, Weng LQ, Song SH, Zhang ZG, Tian SL, Ma R. Characterization of polyetheretherketone-hydroxyapatite nanocomposite materials. Mater Sci Eng A. 2011;528(10-11):3689-3696.

109. Wang L, Weng L, Song S, Zhang Z, Tian S, Ma R. Characterization of polyetheretherketone-hydroxyapatite nanocomposite materials. Mater Sci Eng A. 2011;528:689-696.
110. Ma R, Weng L, Fang L, Luo Z, Song S. Structure and mechanical performance of in situ synthesized hydroxyapatite/polyetheretherketone nanocomposite materials. J Solgel Sci Technol. 2012;62:52-56.

111. Wu X, Liu X, Wei J, Ma J, Deng F, Wei S. Nano-TiO $/ \mathrm{PEEK}_{2}$ bioactive composite as a bone substitute material: in vitro and in vivo studies. Int J Nanomedicine. 2012;7:1215-1225.

112. Li K, Yeung CY, Yeung KWK, Tjong SC. Sintered hydroxyapatite/ polyetheretherketone nanocomposites: mechanical behavior and biocompatibility. Adv Eng Mater. 2012;14:B155-B165.

113. Shortkroff S, Turell MB, Rice K, et al. Cellular response to nanoparticles. In: MRS Proceedings. Cambridge, UK: Cambridge University Press; 2001.

114. Dimitriou R, Jones E, McGonagle D, et al. Bone regeneration: current concepts and future directions. BMC Med. 2011;9:66.

115. Lubick N. Nanosilver toxicity: ions, nanoparticles or both? Environ Sci Technol. 2008;42:8617.

116. Rae T. Tolerance of mouse macrophages in vitro to barium sulfate used in orthopedic bone cement. J Biomed Mater Res. 1977;11:839-846.
International Journal of Nanomedicine

\section{Publish your work in this journal}

The International Journal of Nanomedicine is an international, peerreviewed journal focusing on the application of nanotechnology in diagnostics, therapeutics, and drug delivery systems throughout the biomedical field. This journal is indexed on PubMed Central, MedLine, CAS, SciSearch $\AA$, Current Contents ${ }^{\circledR} /$ Clinical Medicine,

\section{Dovepress}

Journal Citation Reports/Science Edition, EMBase, Scopus and the Elsevier Bibliographic databases. The manuscript management system is completely online and includes a very quick and fair peer-review system, which is all easy to use. Visit http://www.dovepress.com/ testimonials.php to read real quotes from published authors. 